\title{
Hydrothermal Activation of Porous Nitrogen-Doped Carbon Materials for Electrochemical Capacitors and Sodium-Ion Batteries
}

Yuliya V. Fedoseeva ${ }^{1, *} \mathbb{0}$, Egor V. Lobiak ${ }^{1}$, Elena V. Shlyakhova ${ }^{1}$, Konstantin A. Kovalenko ${ }^{1}{ }^{1}$, Viktoriia R. Kuznetsova ${ }^{1}$ (D), Anna A. Vorfolomeeva ${ }^{1}$, Mariya A. Grebenkina ${ }^{1,2}$, Alina D. Nishchakova ${ }^{1}\left(\mathbb{D}\right.$, Anna A. Makarova ${ }^{3}$, Lyubov G. Bulusheva ${ }^{1, *} \mathbb{D}$ and Alexander V. Okotrub ${ }^{1}[$

1 Nikolaev Institute of Inorganic Chemistry SB RAS, 3 Acad. Lavrentiev Ave., 630090 Novosibirsk, Russia; LobiakEV@niic.sbras.ru (E.V.L.); ShlyakhovaEV@niic.sbras.ru (E.V.S.); k.a.kovalenko@niic.nsc.ru (K.A.K.); v.kuznetsova5@g.nsu.ru (V.R.K.); vorfolomeeva@niic.nsc.ru (A.A.V.); grmariya@mail.ru (M.A.G.); nishchakova@niic.nsc.ru (A.D.N.); spectrum@niic.nsc.ru (A.V.O.)

2 Novosibirsk State University, 2 Pirogova Str., 630090 Novosibirsk, Russia

3 Physical Chemistry, Institute of Chemistry and Biochemistry, Free University of Berlin, 14195 Berlin, Germany; anna.makarova@fu-berlin.de

* Correspondence: fedoseeva@niic.nsc.ru (Y.V.F.); bul@niic.nsc.ru (L.G.B.); Tel.: +73-8333-053-52 (Y.V.F. \& L.G.B.)

Received: 30 September 2020; Accepted: 27 October 2020; Published: 29 October 2020

\begin{abstract}
Highly porous nitrogen-doped carbon nanomaterials have distinct advantages in energy storage and conversion technologies. In the present work, hydrothermal treatments in water or ammonia solution were used for modification of mesoporous nitrogen-doped graphitic carbon, synthesized by deposition of acetonitrile vapors on the pyrolysis products of calcium tartrate. Morphology, composition, and textural characteristics of the original and activated materials were studied by transmission electron microscopy, X-ray photoelectron spectroscopy, near-edge X-ray absorption fine structure spectroscopy, infrared spectroscopy, and nitrogen gas adsorption method. Both treatments resulted in a slight increase in specific surface area and volume of micropores and small mesopores due to the etching of carbon surface. Compared to the solely aqueous medium, activation with ammonia led to stronger destruction of the graphitic shells, the formation of larger micropores $(1.4 \mathrm{~nm}$ vs. $0.6 \mathrm{~nm}$ ), a higher concentration of carbonyl groups, and the addition of nitrogen-containing groups. The tests of nitrogen-doped carbon materials as electrodes in $1 \mathrm{M} \mathrm{H}_{2} \mathrm{SO}_{4}$ electrolyte and sodium-ion batteries showed improvement of electrochemical performance after hydrothermal treatments especially when ammonia was used. The activation method developed in this work is hopeful to open up a new route of designing porous nitrogen-doped carbon materials for electrochemical applications.
\end{abstract}

Keywords: porous nitrogen-doped carbon; hydrothermal treatment; XPS; NEXAFS; electrochemical double-layer capacitors; sodium-ion batteries

\section{Introduction}

Growing global demand for energy requires the development of highly performing, inexpensive, and environmentally friendly electrochemical devices. High-energy-density lithium-ion batteries (LIBs) and high-power-density electrochemical double-layer capacitors (EDLCs) are attracting much attention because they are crucial to modern energy technologies [1-5]. Sodium-ion batteries (SIBs) are considered as a promising low-cost alternative for widely used LIBs due to the abundant sodium 
sources. EDLCs are considered highly complementary to batteries for energy storage mainly due to their high-power density, extremely long cycle life, and more reliable safety. One of the major challenges in the development of electrochemical devices is electrode materials with outstanding performances. In this regard, extensive research is needed to establish the structure-property relationships in electrode material and to search for new approaches to achieve the desired material properties.

Carbon-based nanomaterials such as activated carbon, carbon nanotubes, and graphene are effectively used as electrode materials in EDLCs and alkali-metal batteries [6,7]. Small specific surface area and elongated structure of carbon nanotubes and dense assembly of restacked graphene layers do not allow electrolyte and metal ions to penetrate an entire volume of materials, limiting their rate capability performance. Thus far, thin highly porous carbon is the most successful electrode material for EDLCs and SIBs due to its large specific surface area, developed mesopore and micropore structure, low cost, good electrical conductivity, and high chemical stability [6,8]. N-doped carbon materials are more attractive because the nitrogen functionalities increase microporosity, electrical conductivity, and induce pseudocapacitance. High electronegativity of graphitic nitrogen leads to polarization of carbon environment, while nitrogen atoms located at the edges of graphene planes and defects can participate in Faradaic reactions [5,9-13]. In case of alkali-ion batteries, nitrogen functionalities shorten the diffusion path of alkali ions in porous carbon and reduce the volume expansion of carbon materials [14-18]. Carbon-based energy storage devices have numerous advantages over other energy storage technologies but could realize further gains if their electrode materials would be properly optimized. Physical activation by $\mathrm{CO}_{2}$ and chemical activation by $\mathrm{KOH}, \mathrm{ZnCl}_{2}$, and acids are widely used to create pores in carbon materials [19-23]. However, such treatments require high temperatures and/or aggressive reagents, which cause dramatic loss of carbon material and nitrogen incorporated in the carbon lattice $[20,23]$ that may not satisfy the required characteristics of electrode materials.

This research work is devoted to the study of hydrothermal treatment on the structure and composition of $\mathrm{N}$-doped carbon material and the evaluation of the influence of these effects on their electrochemical behavior when used as electrodes for EDLCs and SIBs. For this purpose, $\mathrm{N}$-doped carbon material consisting of thin graphitic shells and a high volume of mesopores produced using calcium tartrate and acetonitrile was chosen [24]. We used water and diluted ammonium hydroxide, safe solvents, to modify N-doped carbon without the use of irrelevant pre-oxidation step. Hydrothermal modification in water with or without the addition of ammonia at moderate temperatures makes the activation procedure effortless, inexpensive, and ecologically friendly. The morphology, composition, atomic, and pore structure of materials were comprehensively studied by transmission electron microscopy (TEM), X-ray photoelectron spectroscopy (XPS), near-edge X-ray absorption fine structure (NEXAFS) spectroscopy, Fourier transformed infrared (FTIR) spectroscopy, and nitrogen gas adsorption technique. The effect of the used hydrothermal modification on the energy storage performance of N-doped carbon nanomaterial in EDLCs and SIBs was thoroughly investigated.

\section{Materials and Methods}

\subsection{Synthesis}

Porous N-doped carbon material (denoted as N-C) was synthesized by the CVD method using conditions described in details elsewhere [24]. Decomposition of calcium tartrate $\left(\mathrm{CaC}_{4} \mathrm{H}_{4} \mathrm{O}_{6}\right)$ at $750{ }^{\circ} \mathrm{C}$ yielded carbon-coated $\mathrm{CaO}$ nanoparticles, which were used for the deposition of acetonitrile $\left(\mathrm{CH}_{3} \mathrm{CN}\right)$ vapors at the same temperature, leading to the formation of graphitic layers. CaO template nanoparticles were removed using a treatment by diluted $\mathrm{HCl}$ for $30 \mathrm{~min}$, the product was washed twice with distilled water to neutral $\mathrm{pH}$, and dried in air at $100{ }^{\circ} \mathrm{C}$ overnight.

The hydrothermal activation of N-C material was carried out in water or aqueous ammonia (9 wt.\%) solution. The N-C sample (50 mg) was placed in a Teflon reactor (Khimprom, Novocheboksarsk, Russia) and water $(5 \mathrm{~mL})$ or the ammonia solution $(8 \mathrm{~mL})$ was added there. The reactor was placed in an autoclave and then heated at a given temperature for $30 \mathrm{~h}$. Hydrothermal treatment in water 
was performed at $200{ }^{\circ} \mathrm{C}$, the saturated vapor pressure was $\sim 15 \mathrm{~atm}$. In order to maintain this vapor pressure during hydrothermal treatment in the ammonia solution, the reactor was heated to $147^{\circ} \mathrm{C}$. The synthesis products were dried in an oven at $80^{\circ} \mathrm{C}$ for $12 \mathrm{~h}$. The samples, obtained by hydrothermal activation in water and the ammonia solution, are denoted N-Cw and N-Ca, respectively.

\subsection{Characterization}

The samples' morphology was investigated by TEM on a JEOL 2010 microscope (JEOL Ltd., Tokyo, Japan) at $200 \mathrm{kV}$ acceleration voltage. Functional groups were identified by FTIR spectroscopy on a Fourier spectrometer Scimitar FTS 2000 (Digilab, Holliston, MA, USA) in the range of 400-4000 $\mathrm{cm}^{-1}$. A specimen $(\sim 1 \mathrm{mg})$ was pressed in a $\mathrm{KBr}$ tablet using the standard procedure. The recorded data were processed by subtracting the nonlinear background arising from optical components and $\mathrm{KBr}$.

XPS and NEXAFS experiment were carried out at the Russian-German Beamline at BESSY II synchrotron radiation facility, Helmholtz-Zentrum Berlin für Materialien und Energie. The XPS spectra were measured using a PHOIBOS 150 electron-energy analyzer (SPECS GmbH, Berlin, Germany) at an energy of monochromatized synchrotron radiation of $830 \mathrm{eV}$ with a resolution of less than $0.5 \mathrm{eV}$. The energy scale was calibrated using the binding energy of $\mathrm{Au} 4 \mathrm{f}_{7 / 2}$ component at $84 \mathrm{eV}$ measured from a clean gold foil. After subtraction of a Shirley background, XPS C 1s and N 1s spectra were fitted using line shapes included Gaussian and Lorentzian functions within Casa XPS software, Version 2.3.15 (Casa Software Ltd., Teignmouth, UK). NEXAFS C K-edge spectra were acquired simultaneously in the total electron yield (TEY) and Auger electron yield (AEY) modes in an energy range of 280-310 eV with $0.1 \mathrm{eV}$ step. The XPS and NEXAFS spectroscopy measurements were carried out at a pressure of $10^{-10}$ Torr and room temperature.

The porous structure was analyzed by a nitrogen adsorption technique using an Autosorb iQ analyzer (Quantachrome Instruments, Boynton Beach, FL, USA) at $77 \mathrm{~K}$. The compound was first activated in a dynamic vacuum using standard "outgas" option of the equipment at $200{ }^{\circ} \mathrm{C}$ during $6 \mathrm{~h}$. $\mathrm{N}_{2}$ adsorption-desorption isotherms were measured within the range of relative pressures of $10^{-6}$ to 0.995 . The specific surface area was calculated from the data obtained based on the conventional BET (Brunauer, Emmett, and Teller) and DFT (Density Functional Theory) models. Pore size distributions were determined using the DFT approach, which gives good agreement between measured and calculated isotherms (fitting error less than $0.5 \%$ ).

\subsection{Electrochemical Measurements}

A three-electrode system was used to measure the performance of EDLC. Carbon material was mixed with an aqueous Teflon F-4D suspension and ethanol, the mixture was homogenized and rolled out into a film. The dried film was applied on a Pt current collector. A Pt foil and an $\mathrm{Ag} / \mathrm{AgCl}$ electrode filled with a saturated $3.5 \mathrm{M} \mathrm{KCl}$ aqueous solution were used as the counter and reference electrodes, respectively. A $1 \mathrm{M} \mathrm{H}_{2} \mathrm{SO}_{4}$ aqueous solution was prepared as an electrolyte. Cyclic voltammetry (CV) curves were recorded on a SP-300 potentiostat/galvanostat (Bio-Logic Science Instrument, Seyssinet-Pariset, France) at different constant scan rates from 2 and $1000 \mathrm{mVs}^{-1}$ in a voltage range from 0 to $+1 \mathrm{~V}$. The long cycling tests were performed using symmetric two-electrode cells at $100 \mathrm{mV} \mathrm{s}^{-1}$. The gravimetric capacitance of a working electrode (C) was calculated from the area of $C V$ curves according to the following formula: $C=\frac{\oint \text { idu }}{2 \cdot \Delta U \cdot V_{s} \cdot m}$, where $i$ is the current $(A)$, du is the differentially small increment of potential $(\mathrm{V}), \Delta \mathrm{U}$ is the voltage window $(\mathrm{V}), \mathrm{V}_{\mathrm{S}}$ is the scan rate $\left(\mathrm{V} \mathrm{s}^{-1}\right)$, and $\mathrm{m}$ is the mass of carbon material $(\mathrm{g})$.

Electrochemical tests of SIBs were conducted in CR2032 coin-type cells assembled in an argon-filled glove box with water and oxygen contents less than 1 ppm. Carbon material was mixed with conductive additive super $\mathrm{P}$ and polyvinylidene difluoride binder (in a weight ratio of 8:1:1) in $\mathrm{N}$-methyl pyrrolidone solvent to form a homogeneous slurry. The slurry was coated onto a $\mathrm{Cu}$ foil and dried at $100{ }^{\circ} \mathrm{C}$ for $12 \mathrm{~h}$ in a vacuum oven. All working electrodes had a standard area of $\sim 0.8 \mathrm{~cm}^{2}$ and weight of the active carbon material of $0.4-0.6 \mathrm{mg}$. Sodium metal sheet was used as a counter 
electrode. Glass fiber piece was used as a separator. The electrolyte was a $1 \mathrm{M}$ solution of $\mathrm{NaClO}_{4}$ in a mixture of ethylene carbonate and dimethyl carbonate (1:1 by volume). The assembled half-cells were galvanostatically charged and discharged between 0.01 and $2.5 \mathrm{~V}$ versus $\mathrm{Na} / \mathrm{Na}^{+}$at different current densities $\left(50,100,250,500\right.$, and $1000 \mathrm{~mA} \mathrm{~g}^{-1}$ ) at room temperature using a Land CT2001 battery test system (NEWARE, HongKong, China). The SP-300 instrument was used to record the CV curves in a voltage range of $2.5-0.01 \mathrm{~V}$ versus $\mathrm{Na} / \mathrm{Na}^{+}$at a potential scan rate of $0.5 \mathrm{mV} \mathrm{s}^{-1}$ and electrochemical impedance spectra (EIS) measurements from $100 \mathrm{kHz}$ to $10 \mathrm{mHz}$ at an AC amplitude of $5 \mathrm{mV}$ at a cell potential of $2.5 \mathrm{~V}$. CV and EIS measurements were performed using the sodium-ion half-cells after their performance of galvanostatic charge-discharge cycles.

\section{Results}

\subsection{Structural Aspect}

TEM images of the samples before and after hydrothermal treatments are compared in Figure 1. The original N-C sample has a sponge-like structure of carbon skeleton and pores ranging from 5 to $30 \mathrm{~nm}$, which are morphologic replications of the template $\mathrm{CaO}$ nanoparticles [24,25] (Figure 1a). High-resolution TEM observation revealed that carbon shells consist of corrugated and disordered graphene-like layers and have a thickness of less than $5 \mathrm{~nm}$ (bottom image in Figure 1a).
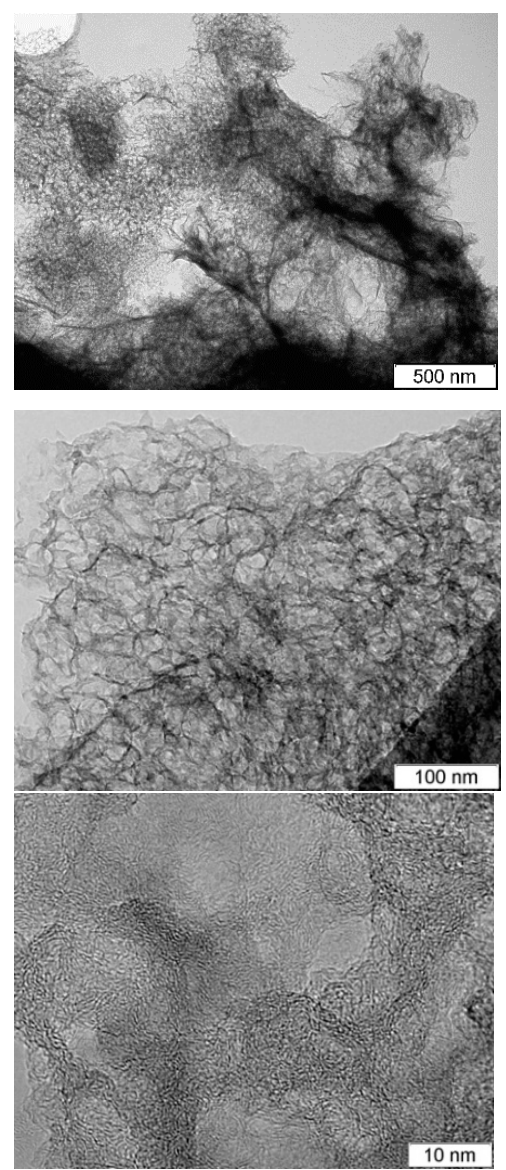

(a)
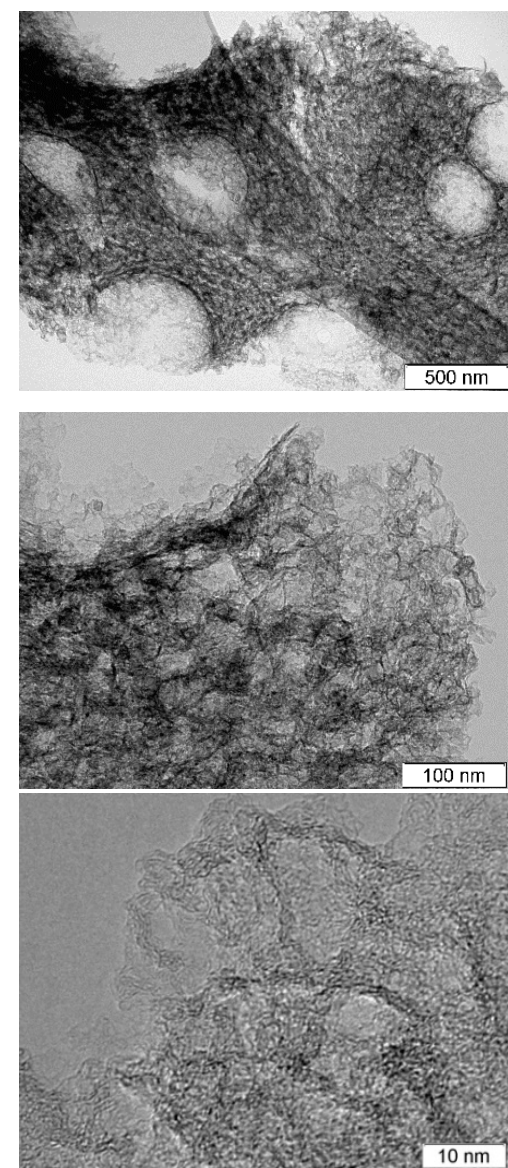

(b)
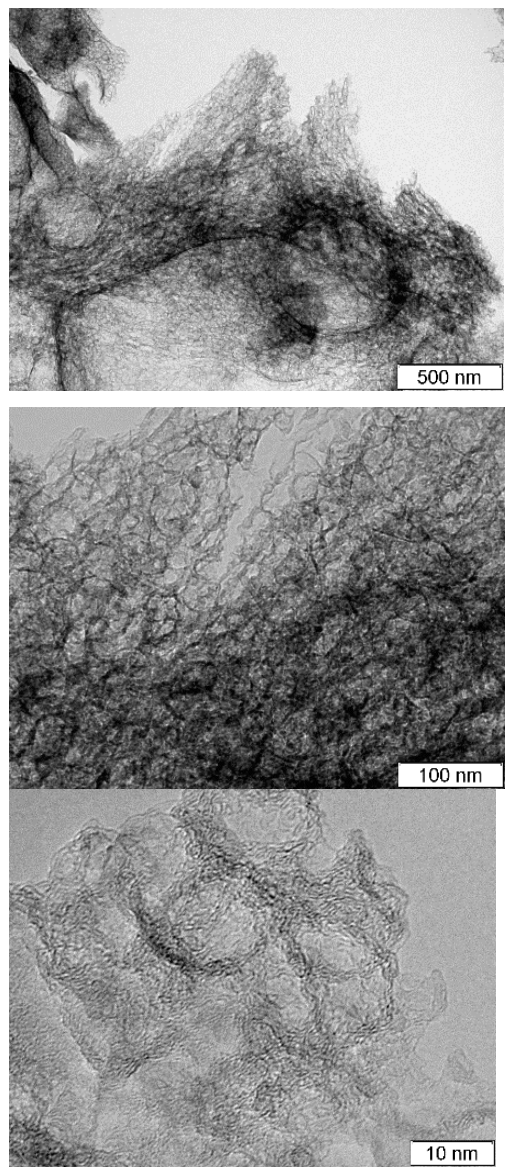

(c)

Figure 1. TEM images taken at various magnifications for (a) porous $\mathrm{N}$-doped carbon material (N-C) and that after hydrothermal treatment in $(\mathbf{b})$ water $(\mathrm{N}-\mathrm{Cw})$ and $(\mathbf{c})$ ammonia solution $(\mathrm{N}-\mathrm{Ca})$.

Decomposition process of the used organic salt of calcium mainly determines the morphology of carbon shells. Similar thin porous carbon shells with a thickness of about $10 \mathrm{~nm}$ were fabricated 
by pyrolysis of sodium citrate used as template and carbon precursors [8]. N-Cw and N-Ca samples retained sponge-like morphology (Figure 1b,c). However, high-resolution TEM images showed that the graphene-like layers became slightly thinner and more defective especially at the edge because of the etching (bottom images in Figure $1 b, c$ ).

Survey XPS spectra of samples detected signals from carbon, oxygen, and nitrogen elements. The surface composition estimated from these spectra is $\mathrm{CN}_{0.06} \mathrm{O}_{0.05}$ for $\mathrm{N}-\mathrm{C}, \mathrm{CN}_{0.05} \mathrm{O}_{0.05}$ for N-Cw, and $\mathrm{CN}_{0.08} \mathrm{O}_{0.02}$ for N-Ca. XPS C 1s spectra were fitted by five components (Figure 2a) and the fitting results are collected in Table 1 . Full width at half maximum (FWHM) is $\sim 1.4 \mathrm{eV}$ for the peak at $284.5 \mathrm{eV}$, assigned to graphite-like $\mathrm{sp}^{2}$ carbon, and $\sim 1.9 \mathrm{eV}$ for other components. A high intensity of the $284.5 \mathrm{eV}$ peak indicates that porous carbon is graphitic mainly, but rather high FWHM value of this component reveals the presence of structural disorders and different orientations of $\mathrm{C}=\mathrm{C}$ bonds. The component at $285.2 \mathrm{eV}$ (denoted as dis.) may indicate the presence of disordered, amorphous, and diamond-like carbon, as well as carbon atoms bonded to hydrogen [26-28]. The surface fraction of this disordered carbon in N-C is 19\%, and it increases to 23 and 36\% in N-Cw and N-Ca, respectively. The components at 286.5 and $287.7 \mathrm{eV}$ can be assigned to carbon atoms bonded with oxygen through single $(\mathrm{C}-\mathrm{O})$ and double $(\mathrm{C}=\mathrm{O})$ bonds, accordingly [28]. The component at $288.8 \mathrm{eV}$ arises from carboxyl groups. Different bonding states between carbon and nitrogen contribute to the $\mathrm{C} 1 \mathrm{~s}$ spectra at energies between 286 and $287 \mathrm{eV}$ [29]. A slight enhance of the component at $287.7 \mathrm{eV}$ and a strong increase of the peak at $285.2 \mathrm{eV}$ were detected in the C 1 s spectra of activated samples (Figure 2a and Table 1). More carbonyl groups and defective states were found on the surface of N-Ca sample.

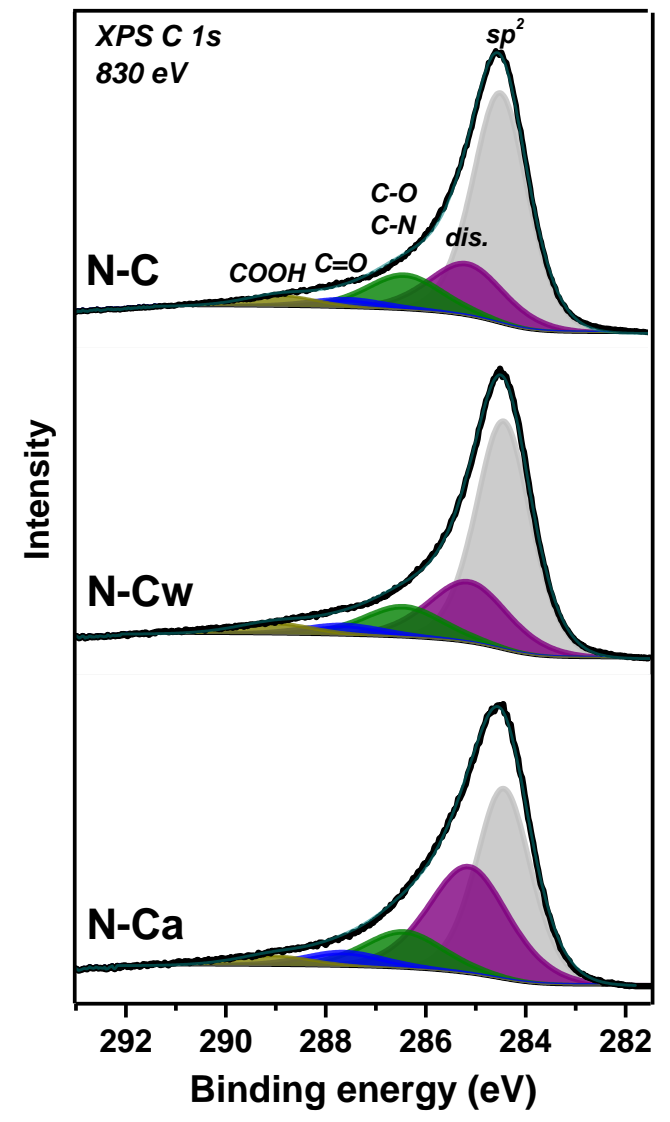

(a)

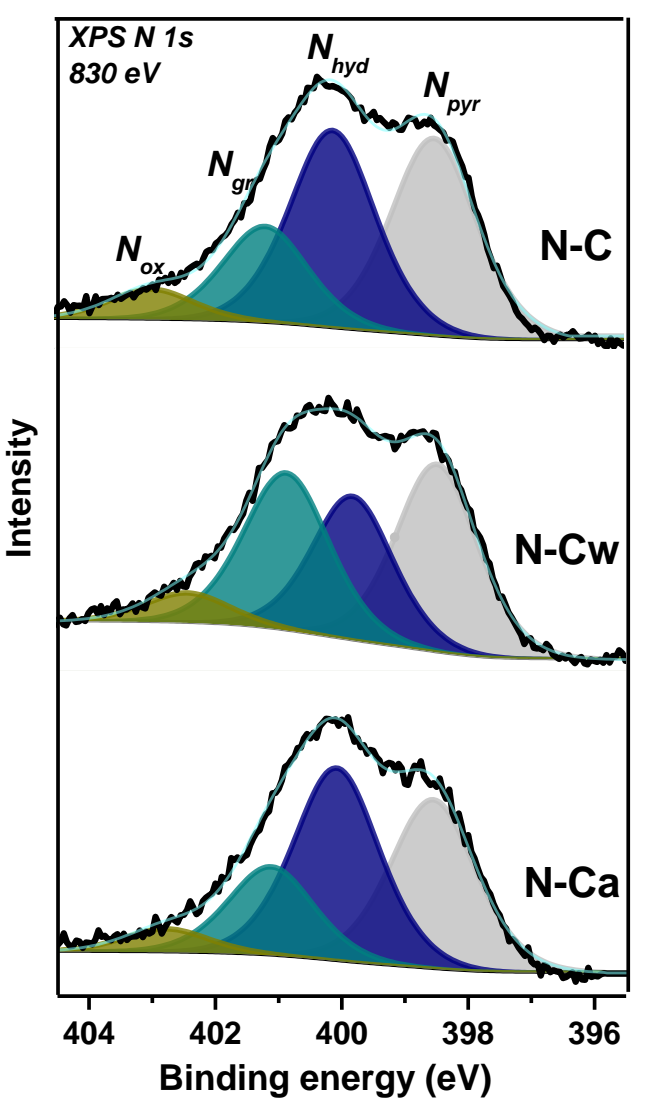

(b)

Figure 2. XPS (a) C 1s and (b) N 1s spectra of porous N-doped carbon material (N-C) and that after hydrothermal treatment in water $(\mathrm{N}-\mathrm{Cw})$ and ammonia solution $(\mathrm{N}-\mathrm{Ca})$. 
Table 1. Energy, assignment and related area of the components in XPS C 1s and N 1s spectra.

\begin{tabular}{cccccccccc}
\hline Energy, eV & \multicolumn{4}{c}{ C 1s XPS } & \multicolumn{5}{c}{ N 1s XPS } \\
\cline { 2 - 10 } & $\mathbf{2 8 4 . 5}$ & $\mathbf{2 8 5 . 2}$ & $\mathbf{2 8 6 . 5}$ & $\mathbf{2 8 7 . 7}$ & $\mathbf{2 8 8 . 8}$ & $\mathbf{3 9 8 . 5}$ & $\mathbf{4 0 0 . 1}$ & $\mathbf{4 0 1 . 2}$ & $\mathbf{4 0 2 . 3}$ \\
\hline Assignment & $\mathbf{s p}^{\mathbf{2}}$ & dis. & C-O/C-N & C=O & COOH & $\mathbf{N}_{\text {pyr }}$ & $\mathbf{N}_{\text {hyd }}$ & $\mathbf{N}_{\mathbf{g r}}$ & $\mathbf{N}_{\mathbf{o x}}$ \\
\hline Related area, $\%$ & 61 & 19 & 13 & 3 & 4 & 38 & 38 & 18 & 6 \\
$\begin{array}{c}\text { N-doped carbon } \\
\text { After treatment in } \mathrm{H}_{2} \mathrm{O}\end{array}$ & 58 & 23 & 12 & 4 & 4 & 36 & 27 & 31 & 6 \\
$\begin{array}{c}\text { After treatment in } \\
\mathrm{NH}_{3} \text { (aq.) }\end{array}$ & 44 & 36 & 12 & 5 & 4 & 36 & 41 & 19 & 5 \\
\hline
\end{tabular}

XPS N 1s spectra revealed at least four different chemical states of nitrogen on the surface of samples (Figure 2b). According to the literature, the peaks located at 398.5, 400.1, 401.2, and $402.3 \mathrm{eV}$ correspond to pyridinic $\left(\mathrm{N}_{\mathrm{pyr}}\right)$, hydrogenated $\left(\mathrm{N}_{\mathrm{hyd}}\right)$, graphitic $\left(\mathrm{N}_{\mathrm{gr}}\right)$, and oxygenated $\left(\mathrm{N}_{\mathrm{ox}}\right)$ nitrogen, respectively [11,30-32]. The quantitative analysis of nitrogen functionalities is given in Table 1 . $\mathrm{N}_{\text {pyr }}$ and $\mathrm{N}_{\text {hyd }}$ states (38\% of each form) are prevalent in the initial sample, which also contains $16 \%$ of $\mathrm{N}_{\mathrm{gr}}$ and $6 \%$ of $\mathrm{N}_{\mathrm{ox}}$. Hydrothermal treatment in water ( $\mathrm{N}-\mathrm{Cw}$ sample) leads mainly to a decrease in $\mathrm{N}_{\text {hyd }}$ fraction and an increase in $\mathrm{N}_{\mathrm{gr}}$ fraction. The use of ammonia in the treatment, on the contrary, increases $\mathrm{N}_{\text {hyd }}$ content and decreases $\mathrm{N}_{\text {gr }}$ content in $\mathrm{N}$-Ca sample.

Figure 3 compares NEXAFS C K-edge spectra of the samples measured in TEY and AEY modes. AEY probes the outermost layers, while TEY detects more bulk states. All spectra show two main peaks at 285.4 and $292.5 \mathrm{eV}$, which are respectively assigned to electron transitions from $1 \mathrm{~s}$ to $\pi^{*}$ - and $\sigma^{*}$-states in graphitic-like structures [33-35]. Broad and smoothed $\pi^{*}$ - and $\sigma^{*}$-resonances in the spectra of N-C sample are a sign of disordering of graphitic layers and this disorder is larger in the surface carbon shells probed by the AEY (Figure 3b) than in depth of the sample (the TEY spectrum in Figure 3a). The spectra of $\mathrm{N}-\mathrm{CW}$ and $\mathrm{N}-\mathrm{Ca}$ show suppression of $\pi^{*}$-resonance. This phenomenon indicates a decrease of the size of conjugated $\pi$-system due to the etching of the graphitic layers or their functionalization. The strongest changes of carbon state are found for N-Ca (Figure 3a,b). Since the lowest intensities of $\pi^{*}$-resonance are observed in the AEY spectra of the activated samples we conclude the modification occurred mainly in the outer surface layers. The states of carbon bonded with functional groups appear between $\pi^{*}$ - and $\sigma^{*}$-resonances. The spectra of $\mathrm{N}-\mathrm{C}$ sample have a peak at $288.3 \mathrm{eV}$, which can be attributed to oxygen-containing functional groups $\pi^{*}(\mathrm{C}=\mathrm{O})$ or $\pi^{*}\left(\mathrm{C}=\mathrm{C}-\mathrm{NH}_{2}\right)[28,36,37]$. The intensity of this peak increases and a new peak at $287.3 \mathrm{eV}$ arises in the spectra of $\mathrm{N}-\mathrm{Cw}$ and $\mathrm{N}-\mathrm{Ca}$. The latter peak corresponds to amine groups $\left(\mathrm{C}-\mathrm{NH}_{\mathrm{x}}\right)$ or aliphatic carbon [38].

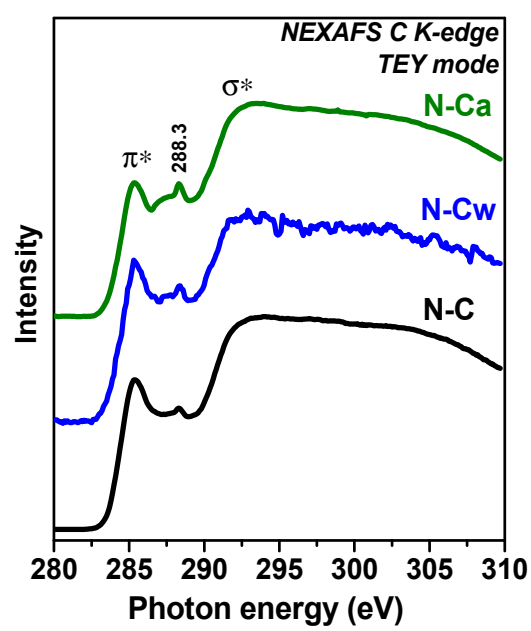

(a)

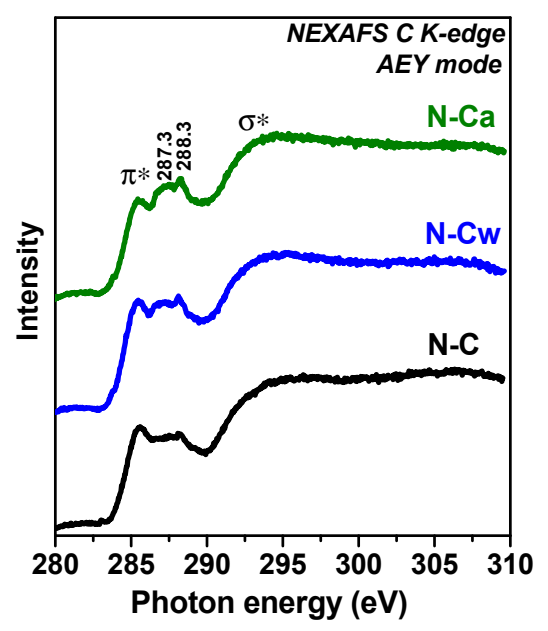

(b)

Figure 3. XPS (a) C 1s and (b) N 1s spectra of porous N-doped carbon material (N-C) and that after hydrothermal treatment in water $(\mathrm{N}-\mathrm{Cw})$ and aqueous ammonia solution $(\mathrm{N}-\mathrm{Ca})$. 
FTIR spectroscopy was additionally invoked to determine changes in the functional composition of N-doped carbon nanomaterial after the applied hydrothermal activations. In Figure 4, the FTIR spectra of the samples show a broad band centered at $3430 \mathrm{~cm}^{-1}$ corresponding to the stretching vibrations of $\mathrm{O}-\mathrm{H}$ bonds from hydroxyl and carboxylic groups and adsorbed water [19]. The peak at $1400 \mathrm{~cm}^{-1}$ appears from $\mathrm{O}-\mathrm{H}$ bending in carboxyl. The band at $1720 \mathrm{~cm}^{-1}$ is assigned to $\mathrm{C}=\mathrm{O}$ stretching vibrations in carbonyl or carboxyl groups [39]. The $\mathrm{C}-\mathrm{O}$ stretches of the hydroxyl and alkoxy groups also raise bands at $1285 \mathrm{~cm}^{-1}$ and $1020-1045 \mathrm{~cm}^{-1}$, respectively [40]. The peak at $1630 \mathrm{~cm}^{-1}$ is due to vibrations of aromatic $\mathrm{C}=\mathrm{C}$ bonds and $\mathrm{C}=\mathrm{N}$ bonds in the basal plane $[24,41,42]$. $\mathrm{N}-\mathrm{H}$ stretching vibrations at $3220 \mathrm{~cm}^{-1}$ and $\mathrm{N}-\mathrm{H}$ in-plane deformations at $1530 \mathrm{~cm}^{-1}$ [43] may overlap with other bands. C-N stretching vibrations can be detected at $1455 \mathrm{~cm}^{-1}$ [44]. A small peak at $880 \mathrm{~cm}^{-1}$ observed in the spectrum of $\mathrm{N}-\mathrm{C}$ originates from $\mathrm{C}-\mathrm{O}-\mathrm{C}$ bonds [45]. Comparison of the FTIR spectra of the samples indicates (1) an increase of the content of $\mathrm{C}=\mathrm{O}$ species in the row $\mathrm{N}-\mathrm{C}<\mathrm{N}-\mathrm{Cw}<\mathrm{N}-\mathrm{Ca}$, (2) conversion of $\mathrm{C}-\mathrm{O}-\mathrm{C}$ bonds present in $\mathrm{N}-\mathrm{C}$ sample to $-\mathrm{OH}$ groups in the activated samples (N-Ca $<\mathrm{N}-\mathrm{Cw})$, (3) removal of alkoxy groups after the hydrothermal treatments, and (4) development of aliphatic C-H bonds with the vibrations at 2980, 2855, and $2920 \mathrm{~cm}^{-1}$ [46] in aqueous ammonia medium (sample $\mathrm{N}-\mathrm{Ca}$ ).

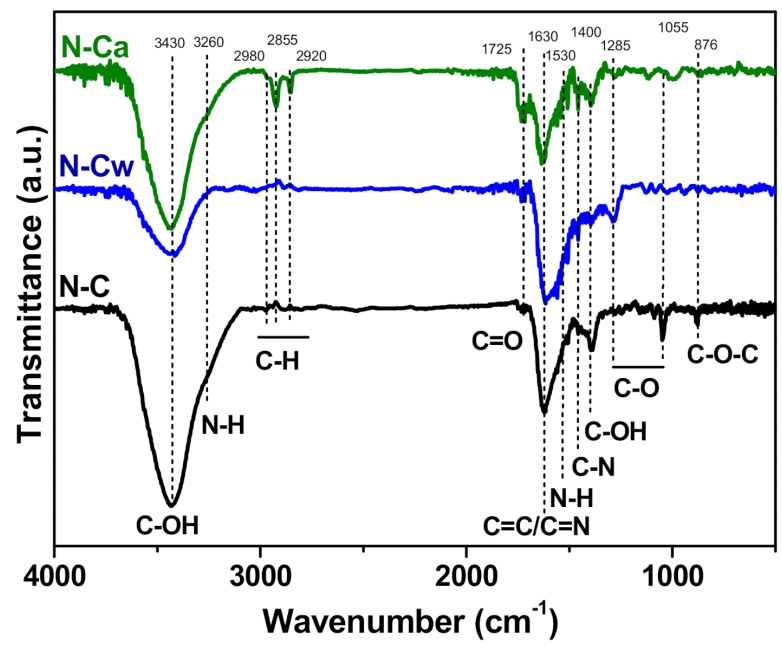

Figure 4. FTIR spectra of porous N-doped carbon material (N-C) and that after hydrothermal treatment in water $(\mathrm{N}-\mathrm{Cw})$ and ammonia solution $(\mathrm{N}-\mathrm{Ca})$.

Nitrogen adsorption-desorption isotherms of the samples are presented in Figure 5a. According to the IUPAC classification [47], they are a combination of Type I and Type IV, which are associated with the adsorption in microporous ( $<2 \mathrm{~nm}$ in width) and mesoporous (2-50 $\mathrm{nm}$ in width) materials, respectively. The steep uptakes at very low $\mathrm{P} / \mathrm{P}_{0}$ are associated with gas adsorption in micropores, while a hysteresis loop at $\mathrm{P} / \mathrm{P}_{0}$ from $\sim 0.5$ to 1.0 arises due to the gas condensation in mesopores of the complex pore network. The values of specific surface area, pore-volume, and total volume of adsorbed nitrogen estimated from the isotherms are listed in Table 2. BET and DFT approaches give quite similar values of the specific surface area, indicating a small number of micropores in the samples. The DFT surface area values increase from $460 \mathrm{~m}^{2} \mathrm{~g}^{-1}$ for $\mathrm{N}-\mathrm{C}$ to $494 \mathrm{~m}^{2} \mathrm{~g}^{-1}$ for N-Cw and $480 \mathrm{~m}^{2} \mathrm{~g}^{-1}$ for N-Ca. The DFT pore volume is $1.4 \mathrm{~cm}^{3} \mathrm{~g}^{-1}$ for $\mathrm{N}-\mathrm{C}, 1.6 \mathrm{~cm}^{3} \mathrm{~g}^{-1}$ for $\mathrm{N}-\mathrm{Cw}$, and $1.3 \mathrm{~cm}^{3} \mathrm{~g}^{-1}$ for $\mathrm{N}-\mathrm{Ca}$. The $\mathrm{N}_{2}$ adsorption $\left(\mathrm{V}_{\mathrm{ads}}\right)$ increases after applied hydrothermal treatment in water and slightly decreases when the aqueous ammonia was used as the medium. It can be suggested that newly developed nitrogen-containing functional groups generated on defects and graphitic edges complicate the penetration of nitrogen molecules fully into microporous space. This assumption can explain the decrease in nitrogen absorption and pore volume for $\mathrm{N}$-Ca sample. 


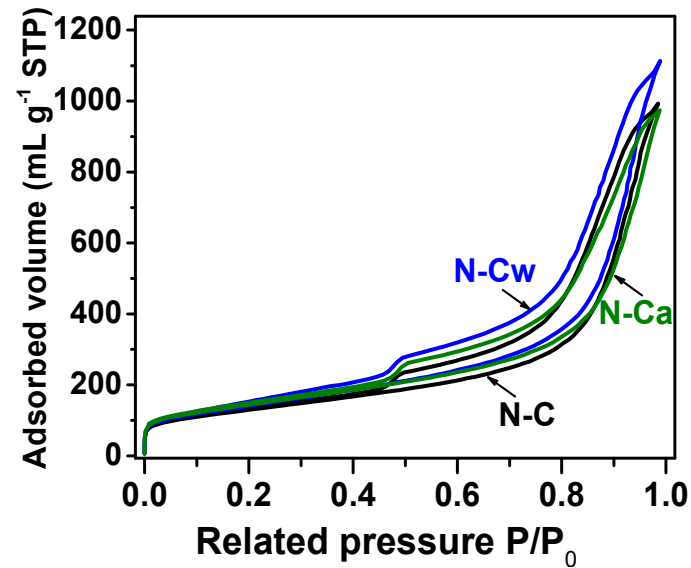

(a)

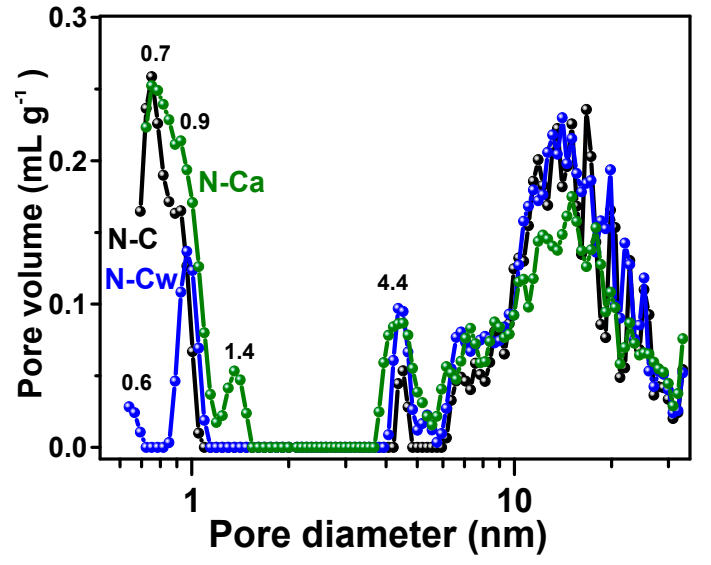

(b)

Figure 5. (a) Nitrogen adsorption-desorption isotherms measured at $77 \mathrm{~K}$; (b) DFT (Density Functional Theory) pore size distributions for N-doped carbon material (N-C) and that after hydrothermal treatment in water $(\mathrm{N}-\mathrm{Cw})$ and ammonia solution $(\mathrm{N}-\mathrm{Ca})$.

Table 2. The parameters of porous structure of samples under investigation.

\begin{tabular}{|c|c|c|c|c|c|}
\hline \multirow{2}{*}{ Sample } & \multicolumn{2}{|c|}{ Specific Surface Area, $\mathrm{m}^{2} \cdot \mathrm{g}^{-1}$} & \multicolumn{2}{|c|}{$\mathrm{V}_{\text {pore}}, \mathrm{cm}^{3} \cdot \mathrm{g}^{-1}$} & \multirow{2}{*}{$\begin{array}{c}\text { Vads }^{\mathrm{a}}, \\
\mathrm{cm}^{3}(\mathrm{STP}) \cdot \mathrm{g}^{-1}\end{array}$} \\
\hline & BET & DFT & Total $^{\mathbf{a}}$ & DFT & \\
\hline $\mathrm{N}$-doped carbon material & 462 & 440 & 1.30 & 1.41 & 840 \\
\hline After treatment in $\mathrm{H}_{2} \mathrm{O}$ & 511 & 494 & 1.45 & 1.56 & 937 \\
\hline After treatment in $\mathrm{NH}_{3}$ (aq.) & 518 & 480 & 1.19 & 1.32 & 768 \\
\hline
\end{tabular}

Pore size distributions showed micropores of about $1 \mathrm{~nm}$, small mesopores with a size of 4-5 nm, and large mesopores with a wide size distribution between 6 and $30 \mathrm{~nm}$ in the samples (Figure $5 b$ ). The mesopores arise as a result of the removal of template calcium oxide nanoparticles with hydrochloric acid treatment, and their size is determined by the temperature of calcium tartrate decomposition [24]. While the micropores more probably originate from atomic defects and incorporated nitrogen atoms in the graphitic lattice. The hydrothermal treatments increased amount of small mesopores $(4-6 \mathrm{~nm})$ in the samples and fraction of $0.9-\mathrm{nm}$ micropores in N-Cw and 1.4-nm micropores in N-Ca. Moreover, the water-assisted treatment created the micropores with a size of $0.6 \mathrm{~nm}$ in N-Cw (Figure 5b). Based on previous works [48,49], the pores between 0.5 and $1 \mathrm{~nm}$, close to the size of solvated hydrogen ions, give the largest contribution to an electric double-layer capacitance of carbon electrode. In the case of SIBs, the holes for the diffusion of solvated sodium ions should be more than $1 \mathrm{~nm}[50]$.

\subsection{Electrochemical Properties}

The results of electrochemical capacitive performances of the samples in $1 \mathrm{M} \mathrm{H}_{2} \mathrm{SO}_{4}$ are shown in Figure 6. The specific capacitance of N-C sample was $125 \mathrm{~F} \mathrm{~g}^{-1}$ at a potential scan rate of $2 \mathrm{mV} \mathrm{s}^{-1}$ and it was reduced to $76 \mathrm{~F} \mathrm{~g}^{-1}$ at $20 \mathrm{mV} \mathrm{s}^{-1}, 53 \mathrm{~F} \mathrm{~g}^{-1}$ at $50 \mathrm{mV} \mathrm{s}^{-1}$ and $34 \mathrm{~F} \mathrm{~g}^{-1}$ at $100 \mathrm{mV} \mathrm{s}^{-1}$ (Figure 6a). The sample N-Cw showed the capacitance of 140, 84, 55, and $35 \mathrm{~F} \mathrm{~g}^{-1}$ at the scan rates of $2,20,50$, and $100 \mathrm{mV} \mathrm{s}^{-1}$, respectively. The sample $\mathrm{N}$-Ca provided 135, 90, 60, and $37 \mathrm{~F} \mathrm{~g}^{-1}$ at $2,20,50$, and $100 \mathrm{mV} \mathrm{s}^{-1}$, respectively, and exhibited the highest capacitance values at scan rates more than $2 \mathrm{mV} \mathrm{s}^{-1}$ among all samples. The developed pore structure, large specific surface area and functional groups of activated samples are responsible for fast ion diffusion and better wettability, therefore leading to higher capacitance and rate capability. Cycle-life tests of the activated samples at $100 \mathrm{mV} \mathrm{s}^{-1}$ showed a loss of initial specific capacitances less than $\sim 5 \%$ during 2000 cycles (inset in Figure 6a). 


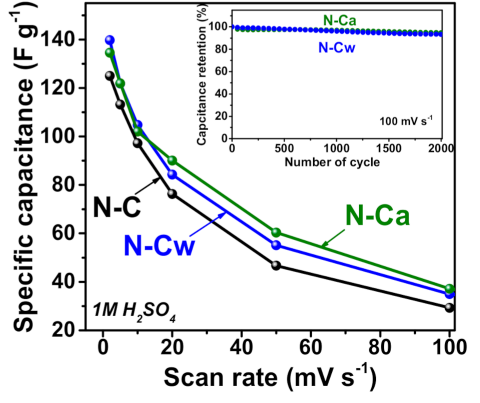

(a)

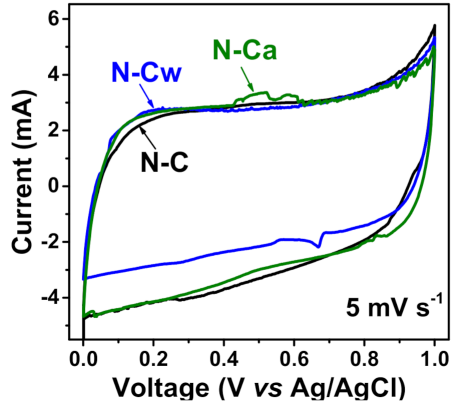

(b)

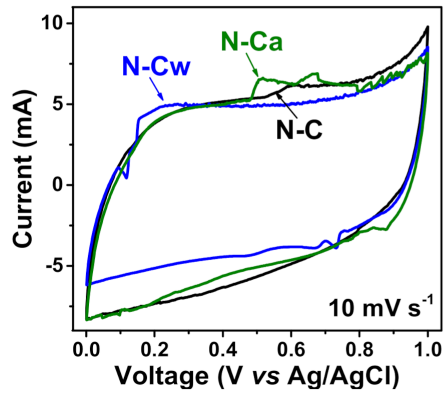

(c)

Figure 6. (a) Specific capacitances and CV curves at scan rates of (b) 5 and (c) $10 \mathrm{mV} \mathrm{s}^{-1}$ of porous $\mathrm{N}$-doped carbon material (N-C) and that after hydrothermal treatment in water $(\mathrm{N}-\mathrm{Cw})$ and ammonia solution (N-Ca). Inset in Figure 6a shows capacitance retention plots for N-C and N-Ca during 2000 cycles at $100 \mathrm{mV} \mathrm{s}^{-1}$.

Figure $6 \mathrm{~b}, \mathrm{c}$ shows the $\mathrm{CV}$ curves of the samples at scan rates of 5 and $10 \mathrm{mV} \mathrm{s}^{-1}$. The $\mathrm{CV}$ curves have a rectangular-like shape but the materials do not function as an ideal EDLC. The peaks appeared on the $\mathrm{CV}$ curves are related to the pseudocapacitance based on Faradaic reactions. The incorporated nitrogen and oxygen atoms typically take part in several redox reactions, thus leading to a rise of overlapped peaks on the $\mathrm{CV}$ curves. These reversible Faradaic processes occur with the proton-coupled electron transfer reaction of nitrogen- or oxygen-containing moieties due to the intercalation and absorption of $\mathrm{H}^{+}$into material depth. Only carbonyl oxygen $(\mathrm{C}=\mathrm{O})$, pyridinic nitrogen $(>\mathrm{N})$, and pyrrolic nitrogen $(>\mathrm{N}-\mathrm{H})$ are electrochemically active in acidic electrolytes $[5,9,11,51]$. At a scan rate of $5 \mathrm{mV} \mathrm{s}^{-1}$, the redox peaks from the reversible reduction/oxidation of carbonyl oxygen appear between 0.2 and $0.4 \mathrm{~V}$ [12], while the Faradaic process involving the pyridinic nitrogen gave a redox peak in the cathodic scans at a higher potential of $\sim 0.7 \mathrm{~V}$ [52]. Thus, for the $\mathrm{CV}$ curves of $\mathrm{N}-\mathrm{C}$, the weak peaks at the potentials of $0.6-0.8 \mathrm{~V}$ in the cathodic scans can be mainly attributed to the pseudocapacitive contribution of $\mathrm{N}_{\text {pyr }}$ or $\mathrm{N}_{\text {hyd }}$. (Figure $6 \mathrm{~b}, \mathrm{c}$ ). These peaks are more pronounced for the activated samples. For $\mathrm{N}-\mathrm{Cw}$, the redox peaks are observed at lower potentials of $0.2-0.4 \mathrm{~V}$ in the cathodic scans (Figure $6 b, c)$. These peaks are attributed to Faradaic capacitance from the carbonyl groups involving protons of the aqueous acidic medium. This result agrees well with FTIR and XPS data, which detected the increasing in the concertation of carbonyl groups after the applied hydrothermal activations in water and aqueous ammonia media (Table 1, Figure 4). The more enhanced pseudocapacitive contribution was observed for $\mathrm{N}-\mathrm{Ca}$. In the $\mathrm{CV}$ curves, the two strong redox peaks observed at cathodic potentials of $0.5-0.6 \mathrm{~V}$ and $0.6-0.7 \mathrm{~V}$ (Figure $6 \mathrm{~b}, \mathrm{c}$ ). Since the concentration of carbonyl and nitrogen functionalities increased in $\mathrm{N}-\mathrm{Ca}$, we suggest that the first peak originates from carbonyl groups, which are near protonated nitrogens and directly connected to an aromatic core. These groups can contribute to the electrochemical proton-coupled redox reaction giving shifted redox peaks in the CV curve. In accordance with the assumption of Wickramaratne et al., the redox reaction could involve pyridone-type nitrogen, where hydrogen migrates to neighbor carbonyl oxygen, and nitrogen bonds to $\mathrm{H}^{+}$[53]. The second redox peak at higher potentials is corresponding to electrochemical reactions involving only nitrogen groups at graphene edges. Thus, capacitance values for $\mathrm{N}-\mathrm{Cw}$ and N-Ca samples are higher than that for N-C owing to the presence of defects and oxygen- and nitrogen-containing functional groups, which increase the proton absorption in the acidic electrolyte.

$\mathrm{Na}$-storage properties of the initial and activated $\mathrm{N}$-doped carbon electrodes are demonstrated by galvanostatic charge-discharge, CVs and EIS (Figures 7 and 8). Figure 7a shows the rate performance of $\mathrm{N}$-doped carbon electrode. N-C sample had a reversible specific capacity of 141, 130,111, 104, and $97 \mathrm{mAh} \mathrm{g}^{-1}$ at a current density of $0.05,0.1,0.25,0.5$, and $1 \mathrm{~A} \mathrm{~g}^{-1}$, respectively. For N-Cw, the specific capacities of 199, 194, 167, 152, and $135 \mathrm{mAh} \mathrm{g}^{-1}$ were achieved at the same current densities. N-Ca electrode material had the best cycling performance, with a specific capacity of $247,240,183$, and $161 \mathrm{mAh} \mathrm{g}^{-1}$ at the same current densities. The capacity loss was less than $\sim 5 \%$ 
for N-Cw and $\sim 8 \%$ for N-Cw after 500 repeating cycles at a current density of $0.5 \mathrm{~A} \mathrm{~g}^{-1}$. Retention of capacity of $65-69 \%$ with an increase in current density from 0.05 to $1 \mathrm{~A} \mathrm{~g}^{-1}$ was found for the initial and activated samples. The observed increase in specific capacity by $40-50 \%$ for $\mathrm{N}-\mathrm{Cw}$ and $60-85 \%$ for $\mathrm{N}-\mathrm{Ca}$ could be caused by the formation of new active sites for Na-ion storage. These values are similar to those reported for various pure and N-doped carbonaceous materials, such as graphitic carbon, hard carbon, carbon fibers and biomass-delivered porous carbon [2,15,18,54-57]. The first cycle capacity loss of $1114 \mathrm{mAh} \mathrm{g}^{-1}$ for N-C, $1768 \mathrm{mAh} \mathrm{g}^{-1}$ for $\mathrm{N}-\mathrm{Cw}$, and $1803 \mathrm{mAh} \mathrm{g}^{-1}$ for N-Ca is attributed to the formation of a solid electrolyte interphase (SEI) layer and an irreversible reaction between the surface functional groups and $\mathrm{Na}^{+}$ions (Figure 7a). Many heteroatom functional groups and defects on the surface of carbon shells favor surface-mediated Na-ion storage. The reduction in the first cycle capacity loss and an increase in the capacity retention can be achieved by optimizing the electrolyte composition through the use of specific additives, changing the parameters of the original material synthesis, or pretreatment of the carbon electrode using similar approaches developed for anode materials in LIBs [58-60].

Figure 7c shows galvanostatic profiles obtained for the three samples at the 55th charge/discharge cycles at the current density of $0.05 \mathrm{~A} \mathrm{~g}^{-1}$ when the formation of SEI layers was completed and the capacities had almost constant values. The profiles are typical for carbon electrodes and consist of two distinct regions: a plateau below $0.2 \mathrm{~V}$ corresponds to the intercalation/de-intercalation of $\mathrm{Na}^{+}$ ions into/from the interlayer space of pseudo-graphitic nanodomains and a slope region above $0.2 \mathrm{~V}$, which is ascribed to reversible binding of $\mathrm{Na}^{+}$ions with carbon defects, edge states or functional groups and their adsorption in the pores [61-65]. The slope region gives the main contribution of about $70 \%$ to the total Na-ion storage capacity of all samples. The main increase in the total capacity of the activated samples occurred due to the rise in the fraction of slope capacity since new defects and micropores act as new adsorption sites for $\mathrm{Na}^{+}$ions. Dependencies of capacities at a potential below $0.2 \mathrm{~V}$ on the current density are shown in Figure $7 \mathrm{~b}$. The plateau capacity contributes no more than $30 \%$ of total values. It is in the range between $43-24 \mathrm{mAh} \mathrm{g}^{-1}$ for N-C, slightly increases to 56-30 $\mathrm{mAh} \mathrm{g}^{-1}$ for $\mathrm{N}-\mathrm{Cw}$, and increases even more to $75-34 \mathrm{mAh} \mathrm{g}^{-1}$ for $\mathrm{N}-\mathrm{Ca}$. The more extended plateau capacities of activated samples are supposed to appear due to the presence of micropores developed during the hydrothermal treatments.

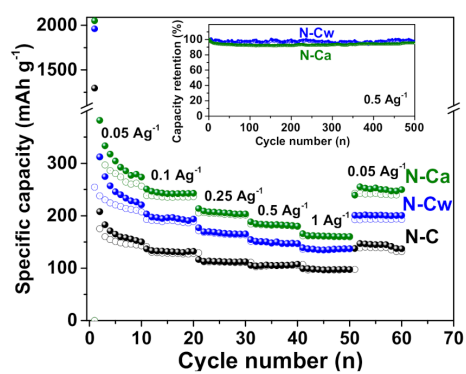

(a)

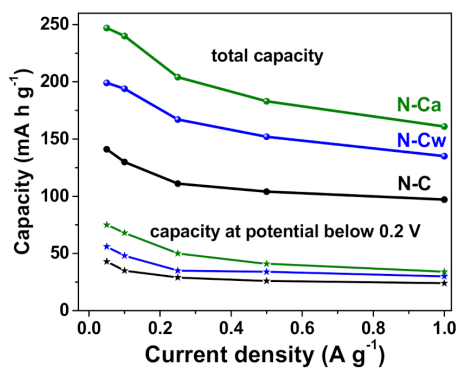

(b)

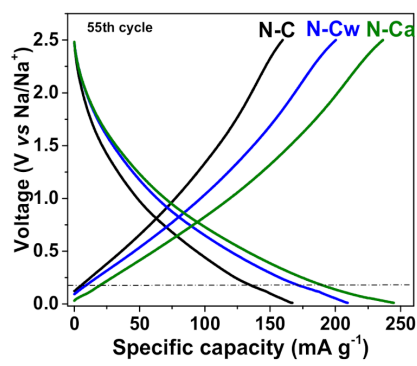

(c)

Figure 7. (a) Rate cycling performance of the samples and capacity retention plots for N-C and N-Ca during 500 cycles at a current density of $0.5 \mathrm{~A} \mathrm{~g}^{-1}$ (inset), (b) total capacity and plateau capacity below $0.2 \mathrm{~V}$ estimated from charge/discharge profiles at different current densities, (c) charge-discharge profiles of 55 th cycles at a current density of $0.05 \mathrm{~A} \mathrm{~g}^{-1}$ for the initial sample (N-C) and that hydrothermally activated in water $(\mathrm{N}-\mathrm{Cw})$ and ammonia solution $(\mathrm{N}-\mathrm{Ca})$. 


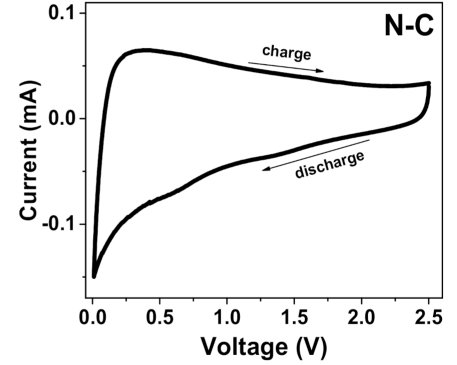

(a)

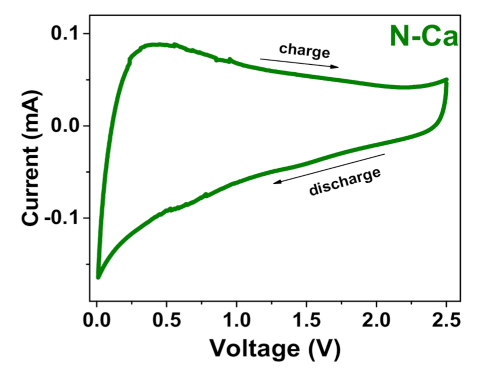

(c)

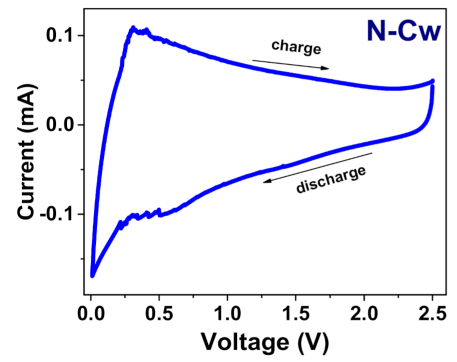

(b)

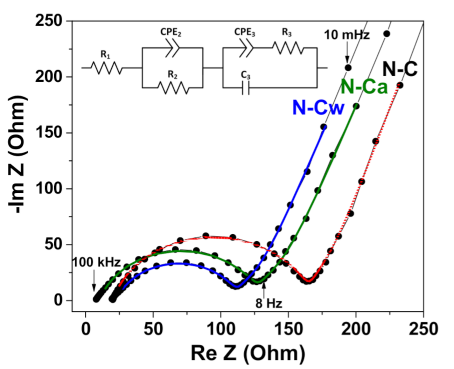

(d)

Figure 8. (a-c) CV curves measured at a scan rate of $0.5 \mathrm{mV} \mathrm{s}^{-1}$ and (d) electrochemical impedance spectra (EIS) curves for the initial sample (N-C) and that after hydrothermal treatment in water (N-Cw) and ammonia solution (N-Ca). The inset in Figure $8 \mathrm{~d}$ shows an equivalent circuit used for the fitting of EIS curves.

$\mathrm{CV}$ curves measured for the samples at a scan rate of $0.5 \mathrm{mV} \mathrm{s}^{-1}$ are presented in Figure $8 \mathrm{a}-\mathrm{c}$. A sharp peak at $0-0.2 \mathrm{~V}$ in the cathodic scans is related to the insertion of $\mathrm{Na}^{+}$ions between the carbon layers, while the broad peak at $0.3 \mathrm{~V}$ in the reverse anodic scans corresponds to the extraction process [51]. The broad peaks at $0.6-0.8 \mathrm{~V}$ in the cathodic scans observed in the CV curves of all samples. These features are commonly not discussed, they can be attributed to the reversible binding of $\mathrm{Na}^{+}$ions with the carboxylate units [66], nitrogen groups [14], or adsorption of $\mathrm{Na}^{+}$ions above the center of monoatomic vacancies [67]. These peaks are more pronounced in the samples after the applied hydrothermal activation; therefore, we suggest that they arouse more likely due to the adsorption of $\mathrm{Na}^{+}$ions in atomic defects than because of interaction with functional groups. It should be noted that we did not detect the redox peaks at 2.3/2.2 V, which Ye et al. attributed to the reversible reaction of sodium ions with $\mathrm{C}=\mathrm{O}$ bonds [68].

EIS measurements were taken in order to understand why N-Cw and N-Ca electrodes exhibit such a superior electrochemical performance as compared to $\mathrm{N}-\mathrm{C}$ one (Figure $8 \mathrm{~d}$ ). The Nyquist plots were modeled using an equivalent electrical circuit presented in the inset of Figure 8d. The ohmic resistance $\left(\mathrm{R}_{1}\right)$ corresponds to the intersection of spectra with $\operatorname{Re}(\mathrm{Z})$ axis at $100 \mathrm{kHz}$. It includes the intrinsic resistance of the current collector and the electrolyte, as well as the contact resistance. A large semicircle in high frequency range corresponds to the charge transfer resistance $\left(R_{2}\right)$ and constant phase element $\left(\mathrm{CPE}_{2}\right)$ for the SEI films. Another indistinct small semicircle and the sloping line in the lower frequency range are associated with the charge-transfer resistance $\left(R_{3}\right)$, the electric double-layer capacitance $\left(C_{3}\right)$ and the constant phase element for solid-state diffusion $\left(\mathrm{CPE}_{3}\right)$ [69-71]. The resistance of SEI films $\left(\mathrm{R}_{2}\right)$ and charge-transfer resistance $\left(\mathrm{R}_{3}\right)$ calculated based on the fitted equivalent electrical circuits are 147 and $60 \mathrm{Ohm}$ for N-C, 91 and $45 \mathrm{Ohm}$ for N-Cw, and 119 and $46 \mathrm{Ohm}$ for N-Ca. The lower $\mathrm{R}_{2}$ and $\mathrm{R}_{3}$ values for the activated samples indicates that the incorporation of carbonyl and nitrogen groups at the edges of graphene surface shells can improve the conductivity of SEI and carbon electrode material because of electron doping effect enhancing the electron transport during the electrochemical $\mathrm{Na}^{+}$ ion insertion/extraction processes. Moreover, the large surface area and pore volume can provide a sufficient electrode-electrolyte interface to storage $\mathrm{Na}^{+}$ions, and thus improve the electrochemical 
performances. $\mathrm{CPE}_{3}\left(\mathrm{Z}=1 / \mathrm{q}(\mathrm{i} \omega)^{\alpha 3}\right)$ is defined by the exponent parameter $\alpha 3$, which describes ion diffusion behavior. According to the fitting results, $\alpha 3$ value is 0.75 for all samples. This value is larger than $\alpha=0.5$ characteristic of the Warburg impedance and it is closer to $\alpha=1$, which is typical for an ideal capacitor. Hence, $\mathrm{Na}^{+}$ions diffuse only into fine surface layers of electrode carbon materials, where they form electric double-layers [71]. The very similar $\mathrm{C}_{3}$ and $\mathrm{CPE}_{3}$ elements describe the low frequency region of the Nyquist plots of all samples. Hence, the samples have comparable capacitive and ion diffusion behaviors, since the used activation procedures modified only surface shells in $\mathrm{N}$-doped carbon material and did not cause significant changes in its morphology and structure.

\section{Discussion}

Structural changes that occurred in porous $\mathrm{N}$-doped carbon material as the result of hydrothermal treatment in water with or without ammonia addition are illustrated in Figure 9 and collected in Table 3. The hydrothermal treatment caused both chemical modification and etching of the surface of carbon shells. FTIR, NEXAFS, and XPS data revealed that hydroxyl and carbonyl groups were attached to the surface of $\mathrm{N}$-doped carbon after the treatment with water. Water acts as a source of hydroxyl functional groups yielding the attachment of these groups at the edges of graphene-like sheets, which, however, can be partially removed under hydrothermal conditions by the protonation process $[72,73]$. By cooling to room temperature, these neighboring hydroxyl groups can be further converted back to water molecules giving carbonyl groups on carbon. Niu et al. revealed that graphite oxide sheets were hydrothermally reduced in water at a temperature above $180^{\circ} \mathrm{C}$, and the lateral size of reduced sheets increased with the temperature [74].

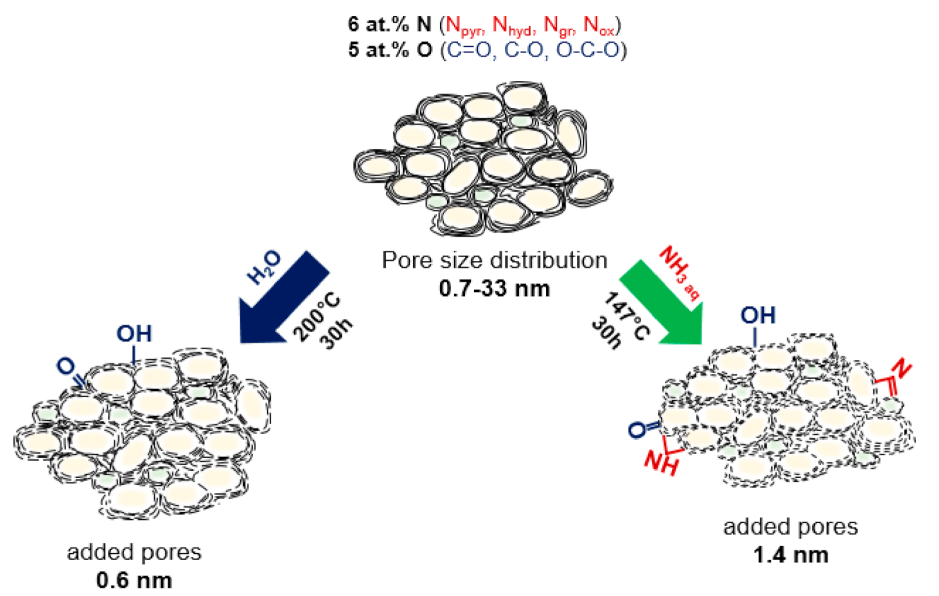

Figure 9. Schematic illustration of the structural evolution of N-doped carbon sheets in the hydrothermal process after the treatment in water and aqueous ammonia solution.

Table 3. Concentration of electrochemically active groups, volume of micropores and small mesopores, and capacitive characteristics of the samples under investigation.

\begin{tabular}{|c|c|c|c|c|c|c|c|}
\hline \multirow[t]{2}{*}{ Sample } & \multicolumn{3}{|c|}{ Concentration, At. $\%$} & \multicolumn{2}{|c|}{$\begin{array}{l}\text { Pore Volume, } \\
10^{-2} \mathrm{~cm}^{3} \cdot \mathrm{g}^{-1}\end{array}$} & \multirow{2}{*}{$\begin{array}{l}\text { Electrochemical Double-Layer } \\
\text { Capacitors (EDLCs) Capacitance At } \\
\qquad 20 \mathrm{mV} \mathrm{s}^{-1}, \mathrm{Fg}^{-1}\end{array}$} & \multirow{2}{*}{$\begin{array}{c}\mathrm{Na}^{+} \text {Storage Capacity At } \\
0.05 \mathrm{~A} \mathrm{~g}^{-1} \\
\mathrm{~mA} \mathrm{~h} \mathrm{~g} \\
\end{array}$} \\
\hline & $\mathrm{C}=\mathrm{O}$ & $\mathbf{N}_{\mathrm{pyr}}$ & $\mathbf{N}_{\text {hyd }}$ & $0-2 \mathrm{~nm}$ & $2-6 \mathrm{~nm}$ & & \\
\hline $\begin{array}{l}\mathrm{N} \text {-doped carbon } \\
\text { material }\end{array}$ & 3 & 2 & 2 & 3 & 1 & 76 & 141 \\
\hline $\begin{array}{l}\text { After treatment } \\
\text { in } \mathrm{H}_{2} \mathrm{O}\end{array}$ & 4 & 2 & 1 & 2 & 3 & 84 & 199 \\
\hline $\begin{array}{l}\text { After treatment } \\
\text { in } \mathrm{NH}_{3} \text { (aq.) }\end{array}$ & 5 & 3 & 3 & 5 & 6 & 90 & 247 \\
\hline
\end{tabular}

The use of aqueous solutions of nitrogen-containing compounds in the hydrothermal process makes it possible to functionalize the carbon surface with nitrogen. For example, the wet chemical route is a very explicit and effective approach to fabricate $\mathrm{N}$-doped graphene through the reactions 
of oxygenated graphite with thiourea [75], urea [76,77], sodium azide [78] and ammonia [79]. The hydrothermal reaction of ammonia solution with the carbon material is analogous to that in pure water. Aqueous ammonia dissociates to $\mathrm{OH}^{-}$and $\mathrm{NH}_{4}{ }^{+}$and $\mathrm{H}^{+}$ions, which decorate the edges of graphene sheets. The total concentration of oxygenated species did not change in $\mathrm{N}-\mathrm{Cw}$, but the fraction of hydroxyl and carbonyl groups increased. According to FTIR and XPS data, N-Ca had the higher number of $\mathrm{N}_{\text {hyd }}$ and $\mathrm{N}_{\mathrm{pyr}}$ edge groups. Additionally, $\mathrm{NH}_{3}$ can react with the oxygen functional groups such as carboxylic and hydroxyl species to form amide and amine groups [76]. These groups may be further dehydrated or decarbonylated with the formation of pyridinic, pyridonic, and pyrrolic nitrogen. The increased number of oxygen atoms double-bonded to carbon in $\mathrm{N}-\mathrm{Ca}$ sample can be explained by their location near $\mathrm{NH}$ groups similar to pyridone $(-\mathrm{NH}-\mathrm{C}=\mathrm{O})$.

The increased fraction of micropores and small mesopores in the activated samples indicates a partial distortion of carbon cage. Previously, it was reported that the hydrothermal treatment in water at $200{ }^{\circ} \mathrm{C}$ for $12 \mathrm{~h}$ resulted in the cutting of single-walled carbon nanotubes, which were firstly oxidized with nitric acid [80]. In comparison, the etching of non-modified carbon nanotubes by water vapor occurred at higher temperatures of $750-950{ }^{\circ} \mathrm{C}$ [81]. We suggest that cutting (breaking of carbon bonds) of the surface of $\mathrm{N}$-doped carbon materials occurs as a result of chemical interaction of water with already existing oxygen-containing groups. The micropores of $0.6 \mathrm{~nm}$ were developed in water medium, while bigger micropores of $1.4 \mathrm{~nm}$ originated in aqueous ammonia solution. Moreover, both activation procedures led to an increase in the fraction of mesopores with a size of 3-6 $\mathrm{nm}$ due to perforation of carbon shells and opening access to previously closed internal cavities. The hydrothermal etching of pre-oxidized graphene and carbon nanotubes have been reported $[7,80,82]$. The cutting mechanism of oxidized graphene sheets suggested by Pan et al. involves the complete breakup of mixed chains composed of basal epoxy and more carbonyl groups under hydrothermal conditions [82]. In our case, the starting material has many oxygen-containing functional groups and defects, which promote etching of carbon shells under the hydrothermal treatment. The edges of the carbon sheets are reactive and readily interact with oxygen species [83-85].

Testing of N-doped carbon materials in the EDLC and SIB cells revealed an improvement of electrochemical performances of hydrothermally activated samples. Noteworthy, that as-grown $\mathrm{N}$-doped carbon had a moderate BET surface area of $462 \mathrm{~m}^{2} \mathrm{~g}^{-1}$ and a small fraction of micropores. Despite these structural characteristics, initial $\mathrm{N}-\mathrm{C}$ material possessed quite high gravimetric capacitances in EDLC of $125 \mathrm{~F} \mathrm{~g}^{-1}$ at $2 \mathrm{mV} \mathrm{s}^{-1}$ and $76 \mathrm{~F} \mathrm{~g}^{-1}$ at $20 \mathrm{mV} \mathrm{s}^{-1}$, which correspond to volumetric capacitances of $6.2 \mathrm{~F} \mathrm{~cm}^{-3}$ and $3.7 \mathrm{~F} \mathrm{~cm}^{-3}$, respectively. The obtained capacitance values are comparable with those for nitrogen-containing carbon electrodes in $1 \mathrm{M} \mathrm{H}_{2} \mathrm{SO}_{4}$ electrolyte, measured in similar three-electrode systems [10], and it is acceptable for practical application. We assume that the fairly good capacitance and rate capability of the N-C electrode are due to the prevailing mesoporosity (pore volume of $1.3 \mathrm{~cm}^{3} \mathrm{~g}^{-1}$ ), which provides quick access of electrolyte ions to the electrode surface especially at high rates $[86,87]$.

The hydrothermal activated samples have increased electrochemical double-layer capacitance and better rate performance. These changes can be attributed to interconnected micro/mesopore-rich structure and larger specific surface, which give the plentiful interfaces for charge accumulation and short paths for ions/electrons. The specific capacitance increases with increasing the surface area and amount of both mesopores and micropores $[49,88]$. According to the current study, Faradaic reactions play an important role in the electric double-layer capacitances of the activated samples due to their increasing number of electrochemically active oxygen and nitrogen functional groups. The direct correlation between the pseudocapacitance and the nitrogen/oxygen content was revealed. The highest concentration of hydrogenated nitrogen and carbonyl groups was found in $\mathrm{N}$-Ca sample, resulting in better pseudocapacitive behavior. Moreover, due to the higher number of micropores and mesopores in the activated samples, their enhanced specific surface areas of $511-518 \mathrm{~m}^{2} \mathrm{~g}^{-1}$ provided the increased specific electric double-layer capacitance. The observed synergetic effect of porosity and nitrogen functional groups in the ammonium-activated sample is in good agreement with the study 
reported by Hulicova-Jurcakova et al., which confirms that pyridinic, pyrrolic nitrogen, and quinone oxygen, presumably located in micropores bigger than $1 \mathrm{~nm}$, have the most pronounced influence on the capacitance due to their pseudocapacitive contributions [48]. Hydrothermal treatment is an approach leading to the incorporation of nitrogen in carbons and improving their EDLC performance. The hydrothermal treatment of graphite oxide in an aqueous solution of urea yielded N-doped graphene with a high nitrogen content (up to $10 \mathrm{at} \%$ ), which had a superior specific capacitance of $326 \mathrm{~F} \mathrm{~g}^{-1}$ in $6 \mathrm{M} \mathrm{KOH}$ electrolyte at a current density of $0.2 \mathrm{~A} \mathrm{~g}^{-1}$ [76]. The hydrothermal treatment of an aqueous dispersion of graphite oxide by $\mathrm{NH}_{3}$ solution $(0.01 \mathrm{vol} . \%)$ resulted in the synthesis of $\mathrm{N}$-doped graphene aerogel with a nitrogen content of 6 at.\% [79]. The aerogel, which underwent the hydrothermal treatment time for $45 \mathrm{~min}$, had the highest gravimetric capacitance of $400 \mathrm{~F} \mathrm{~g}^{-1}$ at $50 \mathrm{~A} \mathrm{~g}^{-1}$ in $1 \mathrm{M} \mathrm{Na}_{2} \mathrm{SO}_{4}$ electrolyte. For N-graphene production, Kim et al. used the microwave radiation for rapid heating of graphite oxide dispersion in an ammonia solution [89]. It appeared that the presence of oxygen-containing groups on the surface of carbon material is not required condition for hydrothermal etching of graphitic layer and nitrogen incorporation. Nitrogen-doped carbon materials prepared by hydrothermal carbonization of aminated tannin showed the highest specific capacitances up to $387.6 \mathrm{~F} \mathrm{~g}^{-1}$ at $2 \mathrm{mV} \mathrm{s}^{-1}[90,91]$.

The rather high Na-ion capacity of the initial N-C sample of $141 \mathrm{mAh} \mathrm{g}^{-1}$ at $0.05 \mathrm{~A} \mathrm{~g}^{-1}$ is due to the large number of mesopores, which facilitate the intercalation of $\mathrm{Na}^{+}$ions [65,92]. In the case of the hydrothermally activated samples, the created defects open new pathways for penetration and accommodation of $\mathrm{Na}^{+}$ions in an interlayer space of carbon shells. Micropores with a larger size of $1.4 \mathrm{~nm}$ formed in N-Ca compared to $0.9 \mathrm{~nm}$ in N-Cw sample. Apparently, the large micropores favor the intercalation of $\mathrm{Na}^{+}$ions. Besides micropores, which provide spaces for storage of $\mathrm{Na}^{+}$ions, the mesopores act as a host for electrolyte and facilitate the ion transport [92]. Yang et al. showed that the capacity of carbon with negligible micropores and abundant mesopores is $83 \%$ higher than the carbon with a few mesopores and abundant micropores [64]. Thus, both micropores and mesopores produced by the hydrothermal treatment facilitate $\mathrm{Na}^{+}$ion intercalation. Nitrogen and oxygen groups also play role in the storage of $\mathrm{Na}^{+}$ions. Our results agree well with previously reported data that the increased concentration of nitrogen, mainly pyridinic form, is one of the reasons for improving Na-ion storage capacity $[14,15,18]$. Piedboeuf et al. found that among the oxygen-containing functionalities only carbonyl groups resulted in the increased storage capacity of $\mathrm{Li}^{+}$ions [93]. That also is in accordance with our results. Actually, N-Ca sample with the highest content of carbonyl and nitrogen groups showed the highest SIB performance.

\section{Conclusions}

A facile and economical hydrothermal treatment approach has been successfully used for chemical activation of as-grown porous N-doped carbon material for various electrochemical applications. By varying the hydrothermal treatment environment, the concentration and nature of functional groups, the number of defects, and pore size distribution can be changed. A treatment in water at $200{ }^{\circ} \mathrm{C}$ for $30 \mathrm{~h}$ resulted in the slight loss of nitrogen groups, mainly by removal of hydrogenated nitrogen, and the addition of carbonyl groups. A hydrothermal treatment in the ammonia solution at $147^{\circ} \mathrm{C}$ for $30 \mathrm{~h}$ caused the incorporation of edge pyridinic and hydrogenated nitrogen groups and the addition of a larger number of carbonyl groups. In both media, the etching of outer carbon shells and the formation of micropores and small mesopores increased specific surface area and pore volume. For the sample activated in aqueous ammonia solution, larger micropores, and more surface defects were formed compared with the sample activated in water. Initial and activated porous $\mathrm{N}$-doped carbon materials were used as electrode materials in EDLCs and SIBs and showed excellent electrochemical performances. The activation-induced micropores and nitrogen- and oxygen-containing functional groups enhanced the energy storage in EDLCs and SIBs due to appearance of more storage sites, faster ion transport and better conductivity of the electrode materials. The synergetic effect of large micropores with a size of $1.4 \mathrm{~nm}$ and an increased content of nitrogen and carbonyl surface edge groups 
in the ammonia-assisted treated $\mathrm{N}$-doped carbon provided the maximum increase in the gravimetric capacitance by $8-15 \mathrm{~F} \mathrm{~g}^{-1}$ at $2-100 \mathrm{~V} \mathrm{~s}^{-1}$ in EDLC and the Na-ion storage capacity by $100 \mathrm{mAh} \mathrm{g}^{-1}$ in SIB. These results are significant for the further design of porous $\mathrm{N}$-doped carbon materials for electrochemical applications.

Author Contributions: Conceptualization, Y.V.F., L.G.B. and A.V.O.; synthesis, E.V.S. and E.V.L.; investigation, Y.V.F., E.V.S., E.V.L., K.A.K., V.R.K., A.A.V., M.A.G., A.D.N. and A.A.M. All authors have read and agree to the published version of the manuscript.

Funding: The work was financially supported by the Russian Science Foundation (grant 19-73-10068).

Acknowledgments: We are grateful to A.V. Ischenko for TEM data and A.A. Shapovalova for the IR spectra. We are grateful to the bilateral Program "Russian-German Laboratory at BESSY II" for assistance in the XPS and NEXAFS measurements.

Conflicts of Interest: The authors declare no conflict of interest. The funders had no role in the design of the study; in the collection, analyses, or interpretation of data; in the writing of the manuscript, or in the decision to publish the results.

\section{References}

1. Li, M.; Lu, J.; Chen, Z.; Amine, K. 30 Years of Lithium-Ion Batteries. Adv. Mater. 2018, 30, 1800561. [CrossRef] [PubMed]

2. Hwang, J.-Y.; Myung, S.-T.; Sun, Y.-K. Sodium-ion Batteries: Present and Future. Chem. Soc. Rev. 2017, 46, 3529-3614. [CrossRef] [PubMed]

3. Poonam Sharma, K.; Arora, A.; Tripathi, S.K. Review of Supercapacitors: Materials and Devices. J. Energy Storage 2019, 21, 801-825. [CrossRef]

4. Wang, Y.; Song, Y.; Xia, Y. Electrochemical Capacitors: Mechanism, Materials, Systems, Characterization and Applications. Chem. Soc. Rev. 2016, 45, 5925-5950. [CrossRef] [PubMed]

5. Yang, D.; Song, Y.; Ye, Y.-J.; Zhang, M.; Sun, X.; Liu, X.-X. Boosting the Pseudocapacitance of Nitrogen-Rich Carbon Nanorod Arrays for Electrochemical Capacitors. J. Mater. Chem. A 2019, 7, 12086-12094. [CrossRef]

6. Jiang, H.; Ye, X.; Zhu, Y.; Wang, L.; Zhao, P.; Yue, Z.; Xie, J.; Wan, Z.; Jia, C. Toward High-Rate Supercapacitor: Preparation of Hierarchical Porous Carbon Binder-Free Electrode with Controllable Texture. Appl. Surf. Sci. 2019, 470, 573-580. [CrossRef]

7. Xiao, B.; Rojo, T.; Li, X. Hard Carbon as Sodium-Ion Battery Anodes: Progress and Challenges. ChemSusChem 2019, 12, 133-144. [CrossRef]

8. Yang, W.; Yang, W.; Ding, F.; Sang, L.; Ma, Z.; Shao, G. Template-Free synthesis of Ultrathin Porous Carbon Shell With Excellent Conductivity for High-Rate Supercapacitors. Carbon 2017, 111, 419-427. [CrossRef]

9. Liu, H.; Song, H.; Chen, X.; Zhang, S.; Zhou, J.; Ma, Z. Effects of Nitrogen- and Oxygen-Containing Functional Groups of Activated Carbon Nanotubes on the Electrochemical Performance in Supercapacitors. J. Power Sources 2015, 285, 303-309. [CrossRef]

10. Deng, Y.; Xie, Y.; Zoua, K.; Ji, X. Review on Recent Advances in Nitrogen-Doped Carbons: Preparations and Applications in Supercapacitors. J. Mater. Chem. A 2016, 4, 1144-1173. [CrossRef]

11. Seredych, M.; Hulicova-Jurcakova, D.; Lu, G.Q.; Bandos, T.J. Surface Functional Groups of Carbons and the Effects of Their Chemical Character, Density and Accessibility to Ions on Electrochemical Performance. Carbon 2008, 46, 1475-1488. [CrossRef]

12. Song, Y.; Li, L.; Wang, Y.; Wang, C.; Guo, Z.; Xia, Y. Nitrogen-Doped Ordered Mesoporous Carbon with a High Surface Area, Synthesized Through Organic-Inorganic Coassembly, and Its Application in Supercapacitors. Chem. Phys. Chem. 2014, 15, 2084-2093. [CrossRef] [PubMed]

13. Zeng, R.; Tang, X.; Huang, B.; Yuan, K.; Chen, Y. Nitrogen-Doped Hierarchically Porous Carbon Materials with Enhanced Performance for Supercapacitor. ChemElectroChem 2018, 5, 515-522. [CrossRef]

14. Agrawal, A.; Janakiraman, S.; Biswas, K.; Venimadhav, A.; Srivastava, S.K.; Ghosh, S. Understanding the Improved Electrochemical Performance of Nitrogen-Doped Hard Carbons as an Anode for Sodium Ion Battery. Electrochim. Acta 2019, 317, 164-172. [CrossRef]

15. Qu, Y.; Guo, M.; Zeng, F.; Zou, C.; Yuan, C.; Zhang, X.; Li, Q.; Lu, H. Synthesis of Nitrogen-Doped Porous Carbon Nanofibers as an Anode Material for High Performance Sodium-Ion Batteries. Solid State Ion. 2019, 337, 170-177. [CrossRef] 
16. Zou, Z.; Jiang, C. Nitrogen-Doped Amorphous Carbon Coated Mesocarbon Microbeads as Excellent High Rate Li Storage Anode Materials. J. Mater. Sci. Technol. 2019, 35, 644-650. [CrossRef]

17. Bulusheva, L.G.; Okotrub, A.V.; Kurenya, A.G.; Zhang, H.; Zhang, H.; Chen, X.; Song, H. Electrochemical Properties of Nitrogen-Doped Carbon Nanotube Anode in Li-ion Batteries. Carbon 2011, 49, 4013-4023. [CrossRef]

18. Liu, S.; Yang, B.; Zhou, J.; Song, H. Nitrogen-Rich Carbon-Onion-Constructed Nanosheets: An Ultrafast and Ultrastable Dual Anode Material for Sodium and Potassium Storage. J. Mater. Chem. A 2019, 7, 18499-18509. [CrossRef]

19. Guo, D.; Xin, R.; Zhang, Z.; Jiang, W.; Hu, G.; Fan, M. N-doped Hierarchically Micro- and Mesoporous Carbons with Superior Performance in Supercapacitors. Electrochim. Acta 2018, 291, 103-113. [CrossRef]

20. Hassan, M.; Haque, E.; Reddy, K.R.; Minett, A.I.; Chen, J.; Gomes, V.G. Edge-Enriched Graphene Quantum Dots for Enhanced Photo-Luminescence and Supercapacitances. Nanoscale 2014, 6, 11988-11994. [CrossRef]

21. Li, Y.; Xiao, Y.; Wang, X.; Cao, M. Enhancement of Lithium Storage Performance of Carbon Microflowers by Achieving a High Surface Area. Chem. Asian J. 2014, 9, 1957-1963. [CrossRef] [PubMed]

22. Xia, K.; Gao, Q.; Jiang, J.; Hu, J. Hierarchical Porous Carbons with Controlled Micropores and Mesopores for Supercapacitor Electrode Materials. Carbon 2008, 46, 1718-1726. [CrossRef]

23. Li, Z.; Guo, K.; Chen, X. Controllable Synthesis of Nitrogen-Doped Mesoporous Carbons for Supercapacitor Applications. RSC Adv. 2017, 7, 30521. [CrossRef]

24. Shlyakhova, E.V.; Bulusheva, L.G.; Kanygin, M.A.; Plyusnin, P.E.; Kovalenko, K.A.; Senkovskiy, B.V.; Okotrub, A.V. Synthesis of Nitrogen-Containing Porous Carbon Using Calcium Oxide Nanoparticles. Phys. Status Solidi B 2014, 251, 2607-2612. [CrossRef]

25. Lapteva, L.L.; Fedoseeva, Y.V.; Shlyakhova, E.V.; Makarova, A.A.; Bulusheva, L.G.; Okotrub, A.V. NEXAFS Spectroscopy Study of Lithium Interaction with Nitrogen Incorporated in Porous Graphitic Material. J. Mater. Sci. 2019, 54, 11168-11178. [CrossRef]

26. Díaz, J.; Paolicelli, G.; Ferrer, S.; Comin, F. Separation of the $\mathrm{sp}^{3}$ and $\mathrm{sp}^{2}$ Components in the C1s Photoemission Spectra of Amorphous Carbon Films. Phys. Rev. B. 1996, 54, 8064-8069. [CrossRef]

27. Mérel, P.; Tabbal, M.; Chaker, M.; Moisa, S.; Margot, J. Direct Evaluation of the $\mathrm{sp}^{3}$ Content in Diamond-Like-Carbon Films by XPS. Appl. Surf. Sci. 1998, 136, 105-110. [CrossRef]

28. Fedoseeva, Y.V.; Pozdnyakov, G.A.; Okotrub, A.V.; Kanygin, M.A.; Nastaushev, Y.V.; Vilkov, O.Y.; Bulusheva, L.G. Effect of Substrate Temperature on the Structure of Amorphous Oxygenated Hydrocarbon Films Grown with a Pulsed Supersonic Methane Plasma Flow. Appl. Surf. Sci. 2016, 385, 464-471. [CrossRef]

29. Titantah, J.T.; Lamoen, D. Carbon and Nitrogen 1s Energy Levels in Amorphous Carbon Nitride Systems: XPS Interpretation Using First-Principles. Diam. Relat. Mater. 2007, 16, 581-588. [CrossRef]

30. Bulusheva, L.G.; Okotrub, A.V.; Fedoseeva, Y.V.; Kurenya, A.G.; Asanov, I.P.; Vilkov, O.Y.; Koós, A.A.; Grobert, N. Controlling Pyridinic, Pyrrolic, Graphitic, and Molecular Nitrogen in Multi-Wall Carbon Nanotubes using Precursors with Different N/C Ratios in Aerosol Assisted Chemical Vapor Deposition. Phys. Chem. Chem. Phys. 2015, 17, 23741-23747. [CrossRef]

31. Scardamaglia, M.; Aleman, B.; Amati, M.; Ewels, C.; Pochet, P.; Reckinger, N.; Colomer, J.-F.; Skaltsas, T.; Tagmatarchis, N.; Snyders, R.; et al. Nitrogen Implantation of Suspended Graphene Flakes: Annealing Effects and Selectivity of $\mathrm{sp}^{2}$ Nitrogen Species. Carbon 2014, 73, 371-381. [CrossRef]

32. Okotrub, A.V.; Fedorovskaya, E.O.; Senkovskiy, B.V.; Bulusheva, L.G. Nitrogen Species in Few-Layer Graphene Produced by Thermal Exfoliation of Fluorinated Graphite Intercalation Compounds. Phys. Status Solidi B 2015, 252, 2444-2450. [CrossRef]

33. Rosenberg, R.A.; Love, P.J.; Rehn, V. Polarization-Dependent C(K) Near-Edge X-ray-Absorption Fine Structure of Graphite. Phys. Rev. B 1986, 33, 4034-4037. [CrossRef]

34. Zou, Y.; Tang, J.C. Multiple-Scattering Approaches to Carbon K-Shell Near-Edge X-ray Absorption Fine Structure of Graphite. J. Phys. Condens. Matter 1994, 6, 2949-2956. [CrossRef]

35. Fedoseeva, Y.V.; Okotrub, A.V.; Koroteev, V.O.; Borzdov, Y.M.; Palyanov, Y.N.; Shubin, Y.V.; Maksimovskiy, E.A.; Makarova, A.A.; Münchgesang, W.; Bulusheva, L.G.; et al. Graphitization of ${ }^{13} \mathrm{C}$ enriched Fine-Grained Graphitic Material Under High-Pressure Annealing. Carbon 2019, 141, 323-330. [CrossRef] 
36. Latham, K.G.; Simone, M.I.; Dose, W.M.; Allen, J.A.; Donne, S.W. Synchrotron Based NEXAFS Study on Nitrogen Doped Hydrothermal Carbon: Insights into Surface Functionalities and Formation Mechanisms. Carbon 2017, 114, 566-578. [CrossRef]

37. Ikeura-Sekiguchi, H.; Sekiguchi, T. Adsorption Structure of Formic Acid on Si(100) Studied by Surface NEXAFS. Surf. Sci. 1999, 433, 549-553. [CrossRef]

38. Solomon, D.; Lehmann, J.; Kinyangi, J.; Liang, B.; Schäfer, T. Carbon K-Edge NEXAFS and FTIR-ATR Spectroscopic Investigation of Organic Carbon Speciation in Soils. Soil Sci. Soc. Am. J. 2005, 69, 107-119. [CrossRef]

39. Pan, N.; Guan, D.; Yang, Y.; Huang, Z.; Wang, R.; Jin, Y.; Xia, C. A Rapid Low-Temperature Synthetic Method Leading to Large-Scale Carboxyl Graphene. Chem. Eng. J. 2014, 236, 471-479. [CrossRef]

40. Dey, R.S.; Hajra, S.; Sahu, R.K.; Raj, C.R.; Panigrahi, M.K. A Rapid Room Temperature Chemical Route for the Synthesis of Graphene: Metal-Mediated Reduction of Graphene Oxide. Chem. Commun. 2012, 48, 1787-1789. [CrossRef]

41. AlQadhi, N.F.; AlSuhaimi, A.O. Chemically Functionalized Activated Carbon With 8-Hydroxyquinoline Using Aryldiazonium Salts/Diazotization Route: Green Chemistry Synthesis for Oxins-Carbon Chelators. Arab. J. Chem. 2020, 13, 1386-1396. [CrossRef]

42. Geng, D.; Yang, S.; Zhang, Y.; Yang, J.; Liu, J.; Li, R.; Sham, T.-K.; Sun, X.; Ye, S.; Knights, S. Nitrogen Doping Effects on the Structure of Graphene. Appl. Surf. Sci. 2011, 257, 9193-9198. [CrossRef]

43. Zhao, Z.; Yang, Z.; Hu, Y.; Li, J.; Fan, X. Multiple Functionalization of Multi-Walled Carbon Nanotubes With Carboxyl and Amino Groups. Appl. Surf. Sci. 2013, 276, 476-481. [CrossRef]

44. He, Z.; Su, A.; Gao, C.; Zhou, Z.; Pan, C.; Liu, S. Carbon Paper Modified by Hydrothermal Ammoniated Treatment for Vanadium Redox Battery. Ionics 2013, 19, 1021-1026. [CrossRef]

45. Nekahi, A.; Marashi, P.H.; Haghshenas, D. Transparent Conductive Thin Film of Ultra Large Reduced Graphene Oxide Monolayers. Appl. Surf. Sci. 2014, 295, 59-65. [CrossRef]

46. Ferreira, F.V.; Brito, F.S.; Franceschi, W.; Simonetti, E.A.N.; Cividanes, L.S.; Chipara, M.; Lozano, K. Functionalized Graphene Oxide as Reinforcement in Epoxy Based Nanocomposites. Surf. Interfaces 2018, 10, 100-109. [CrossRef]

47. Thommes, M.; Kaneko, K.; Neimark, A.V.; Olivier, J.P.; Rodriguez-Reinoso, F.; Rouquerol, J.; Sing, K.S.W. Physisorption of Gases, with Special Reference to the Evaluation of Surface Area and Pore Size Distribution. Pure Appl. Chem. 2015, 87, 1051-1069. [CrossRef]

48. Hulicova-Jurcakova, D.; Seredych, M.; Lu, G.Q.; Bandosz, T.J. Combined Effect of Nitrogen- and Oxygen-Containing Functional Groups of Microporous Activated Carbon on Its Electrochemical Performance in Supercapacitors. Adv. Funct. Mater. 2009, 19, 438-447. [CrossRef]

49. Chmiola, J.; Yushin, G.; Gogotsi, Y.; Portet, C.; Simon, P.; Taberna, P.L. Anomalous Increase in Carbon Capacitance at Pore Sizes Less Than 1 Nanometer. Science 2006, 313, 1760-1763. [CrossRef]

50. Kim, H.; Hong, J.; Yoon, G.; Kim, H.; Park, K.-Y.; Park, M.-S.; Yoon, W.-S.; Kang, K. Sodium Intercalation Chemistry in Graphite. Energy Environ. Sci. 2015, 8, 2963-2969. [CrossRef]

51. Popov, K.M.; Fedoseeva, Y.V.; Kokhanovskaya, O.A.; Razd'yakonova, G.I.; Smirnov, D.A.; Bulusheva, L.G.; Okotrub, A.V. Functional Composition and Electrochemical Characteristics of Oxidized Nanosized Carbon. J. Struct. Chem. 2017, 58, 1187-1195. [CrossRef]

52. Bulusheva, L.G.; Fedorovskaya, E.O.; Kurenya, A.G.; Okotrub, A.V. Supercapacitor Performance of Nitrogen-Doped Carbon Nanotube Arrays. Phys. Status Solidi B 2013, 12, 2586-25911. [CrossRef]

53. Wickramaratne, N.P.; Xu, J.; Wang, M.; Zhu, L.; Dai, L.; Jaroniec, M. Nitrogen Enriched Porous Carbon Spheres: Attractive Materials for Supercapacitor Electrodes and $\mathrm{CO}_{2}$ Adsorption. Chem. Mater. 2014, 26, 2820-2828. [CrossRef]

54. Xu, Z.-L.; Park, J.; Yoon, G.; Kim, H.; Kang, K. Graphitic Carbon Materials for Advanced Sodium-Ion Batteries. Small Methods 2018, 1800227. [CrossRef]

55. Balogun, M.-S.; Luo, Y.; Qiu, W.; Liu, P.; Tong, Y. A Review of Carbon Materials and Their Composites with Alloy Metals for Sodium Ion Battery Anodes. Carbon 2016, 98, 162-178. [CrossRef]

56. Saurel, D.; Orayech, B.; Xiao, B.; Carriazo, D.; Li, X.; Rojo, T. From Charge Storage Mechanism to Performance: A Roadmap toward High Specific Energy Sodium-Ion Batteries through Carbon Anode Optimization. Adv. Energy Mater. 2018, 8, 1703268. [CrossRef] 
57. Liu, T.; Li, X. Biomass-Derived Nanostructured Porous Carbons for Sodium Ion Batteries: A Review. Mater. Technol. 2019, 34, 232-245. [CrossRef]

58. Wang, C.; Appleby, A.J.; Little, F.E. Irreversible Capacities of Graphite Anode for Lithium-Ion Batteries. J. Electroanal. Chem. 2002, 519, 9-17. [CrossRef]

59. Buiel, E.; Dahnt, J.R. Reduction of the Irreversible Capacily in Hard-Carbon Anode Materials Prepared from Sucrose for Li-Ion Batteries. J. Electrochem. Soc. 1998, 145, 1977-1981. [CrossRef]

60. Kulovaz, T.L.; Skundin, A.M. Combined Method for Reducing Irreversible Capacity of the Negative Graphite Electrode in Lithium-Ion Battery. Russ. J. Electrochem. 2004, 40, 16-21. [CrossRef]

61. Qiu, S.; Xiao, L.; Sushko, M.L.; Han, K.S.; Shao, Y.; Yan, M.; Liang, X.; Mai, L.; Feng, J.; Cao, Y.; et al. Manipulating Adsorption-Insertion Mechanisms in Nanostructured Carbon Materials for High-Efficiency Sodium Ion Storage. Adv. Energy Mater. 2017, 7, 1700403. [CrossRef]

62. Ghimbeu, C.M.; Górka, J.; Simone, V.; Simonin, L.; Martinet, S.; Vix-Guterl, C. Insights on the Na ${ }^{+}$ion Storage Mechanism in Hard Carbon: Discrimination Between the Porosity, Surface Functional Groups and Defects. Nano Energy 2018, 44, 327-335. [CrossRef]

63. Alvin, S.; Yoon, D.; Chandra, C.; Cahyadi, H.S.; Park, J.-H.; Chang, W.; Chung, K.Y.; Kim, J. Revealing Sodium Ion Storage Mechanism in Hard Carbon. Carbon 2019, 145, 67-81. [CrossRef]

64. Yang, L.; Hu, M.; Zhang, H.; Yang, W.; Lv, R. Pore Structure Regulation of Hard Carbon: Towards Fast and High-Capacity Sodium-Ion Storage. J. Colloid Interface Sci. 2020, 566, 257-264. [CrossRef] [PubMed]

65. Dong, Y.; Lin, X.; Wang, D.; Yuan, R.; Zhang, S.; Chen, X.; Bulusheva, L.G.; Okotrub, A.V.; Song, H. Modulating the Defects of Graphene Blocks by Ball-Milling for Ultrahigh Gravimetric and Volumetric Performance and Fast Sodium Storage. Energy Storage Mater. 2020, 30, 287-295. [CrossRef]

66. Zhao, R.; Cao, Y.L.; Ai, X.P.; Yang, H.X. Reversible Li and Na Storage Behaviors of Perylenetetracarboxylates as Organic Anodes for Li- and Na-ion Batteries. J. Electroanal. Chem. 2013, 688, 93-97. [CrossRef]

67. Tsai, P.; Chung, S.-C.; Lin, S.; Yamada, A. Ab Initio Study of Sodium Intercalation into Disordered Carbon. Mater. Chem. A 2015, 3, 9763-9768. [CrossRef]

68. Ye, J.; Zhao, H.; Kang, M.; Song, W.; Kong, Q.; Chen, C.; Wu, R.; Mia, J.; Li, Z. Defect Formation-Induced Tunable Evolution of Oxygen Functional Groups for Sodium Storage in Porous Graphene. Chem. Commun. 2020, 56, 1089-1092. [CrossRef]

69. Wang, C.; Appleby, A.J.; Little, F.E. Electrochemical Impedance Study of Initial Lithium Ion Intercalation into Graphite Powders. Electrochim. Acta 2001, 46, 1793-1813. [CrossRef]

70. Xia, B.; Yang, Y.; Zhou, J.; Chen, G.; Liu, Y.; Wang, H.; Wang, M.; Lai, Y. Using Self Organizing Maps to Achieve Lithium-Ion Battery Cells Multi-Parameter Sorting Based on Principle Components Analysis. Energies 2019, 12, 2980. [CrossRef]

71. Vyroubal, P.; Kazda, T. Equivalent Circuit Model Parameters Extraction for Lithium Ion Batteries Using Electrochemical Impedance Spectroscopy. J. Energy Storage 2018, 15, 23-31. [CrossRef]

72. Zhou, Y.; Bao, Q.; Tang, L.A.L.; Zhong, Y.; Loh, K.P. Hydrothermal Dehydration for the “Green" Reduction of Exfoliated Graphene Oxide to Graphene and Demonstration of Tunable Optical Limiting Properties. Chem. Mater. 2009, 21, 2950-2956. [CrossRef]

73. Díez, N.; Śliwak, A.; Gryglewicz, S.; Grzyb, B.; Gryglewicz, G. Enhanced Reduction of Graphene Oxide by High Pressure Hydrothermal Treatment. RSC Adv. 2015, 5, 81831-81837. [CrossRef]

74. Niu, Y.; Fang, Q.; Zhang, X.; Zhang, P.; Li, Y. Reduction and Structural Evolution of Graphene Oxide Sheets Under Hydrothermal Treatment. Phys. Lett. A 2016, 380, 3128-3132. [CrossRef]

75. Zhao, J.; Ren, W.; Cheng, H.-M. Graphene Sponge for Efficient and Repeatable Adsorption and Desorption of Water Contaminations. J. Mater. Chem. 2012, 22, 20197-20202. [CrossRef]

76. Sun, L.; Wang, L.; Tian, C.; Tan, T.; Xie, Y.; Shi, K.; Li, M.; Fu, H. Nitrogen-Doped Graphene with High Nitrogen Level via a One-Step Hydrothermal Reaction of Graphene Oxide with Urea for Superior Capacitive Energy Storage. RSC Adv. 2012, 2, 4498-4506. [CrossRef]

77. Guanghui, W.; Ruiyi, L.; Zaijun, L.; Junkang, L.; Zhiguo, G.; Guangli, W. N-doped Graphene/Graphite Composite as a Conductive Agent-Free Anode Material for Lithium Ion Batteries with Greatly Enhanced Electrochemical Performance. Electrochim. Acta 2015, 171, 156-164. [CrossRef]

78. Zhang, Q.; Zhou, K.; Lei, J.; Hu, W. Nitrogen Dual-Doped Porous Carbon Fiber: A Binder-Free and High Performance Flexible Anode for Lithium Ion Batteries. Appl. Surf. Sci. 2019, 467-468, 992-999. [CrossRef] 
79. Rodríguez-Mata, V.; Hernández-Ferrer, J.; Carrera, C.; Benito, A.M.; Maser, W.K.; García-Bordejé, E. Towards High-Efficient Microsupercapacitors Based on Reduced Graphene Oxide with Optimized Reduction Degree. Energy Storage Mater. 2020, 25, 740-749. [CrossRef]

80. Dong, Y.; Pang, H.; Ren, S.; Chen, C.; Chi, Y.; Yu, T. Etching Single-Wall Carbon Nanotubes into Green and Yellow Single-Layer Graphene Quantum Dots. Carbon 2013, 64, 245-251. [CrossRef]

81. Xiao, Z.; Yang, Z.; Nie, H.; Lu, Y.; Yang, K.; Huang, S. Porous Carbon Nanotubes Etched by Water Steam for High-Rate Large-Capacity Lithium-Sulfur Batteries. J. Mater. Chem. A 2014, 2, 8683-8689. [CrossRef]

82. Pan, D.; Zhang, J.; Li, Z.; Wu, M. Hydrothermal Route for Cutting Graphene Sheets into Blue-Luminescent Graphene Quantum Dots. Adv. Mater. 2010, 22, 734-738. [CrossRef] [PubMed]

83. Kvashnin, A.G.; Avramov, P.V.; Sakai, S.; Nechaev, Y.S.; Sorokin, P.B. Estimation of Graphene Surface Stability Against the Adsorption of Environmental and Technological Chemical Agents. Phys. Status Solidi B 2017, 254, 1600702. [CrossRef]

84. Sanyal, B.; Eriksson, O. Molecular Adsorption in Graphene with Divacancy Defects. Phys. Rev. B 2009, 79, 113409. [CrossRef]

85. Fedoseeva, Y.V.; Bulusheva, L.G.; Okotrub, A.V.; Vyalikh, D.V.; Fonseca, A. A Comparative Study of Argon Ion Irradiated Pristine and Fluorinated Single-Wall Carbon Nanotubes. J. Chem. Phys. 2010, 133, 224706. [CrossRef]

86. Yamada, Y.; Tanaike, O.; Liang, T.T.; Hatori, H.; Shiraishi, S.; Oya, A. Electric Double Layer Capacitance Performance of Porous Carbons Prepared by Defluorination of Polytetrafluoroethylene with Potassium. Electrochem. Solid State Lett. 2002, 5, 283-285. [CrossRef]

87. Yoon, S.; Lee, J.; Hyeon, T.; Oh, S.M. Electric Double-Layer Capacitor Performance of a New Mesoporous Carbon. J. Electrochem. Soc. 2000, 147, 2507-2512. [CrossRef]

88. Kim, C.-Y.; Jang, A.R.; Cho, K.Y. Optimization of Pore Structures and Supercapacitor Properties of Carbon Aerogel Electrodes. Asian J. Chem. 2012, 24, 4205-4212.

89. Kim, I.T.; Shin, M.W. Synthesis of Nitrogen-Doped Graphene via Simple Microwave-Hydrothermal Process. Mater. Lett. 2013, 108, 33-36. [CrossRef]

90. Braghiroli, F.L.; Fierro, V.; Szczurek, A.; Stein, N.; Parmentier, J.; Celzard, A. Hydrothermally Treated Aminated Tanninas Precursor of N-doped Carbon Gels for Supercapacitors. Carbon 2015, 90, 63-74. [CrossRef]

91. Braghiroli, F.L.; Fierro, V.; Izquierdo, M.T.; Parmentier, J.; Pizzi, A.; Celzard, A. Nitrogen-Doped Carbon Materials Produced From Hydrothermally Treated Tannin. Carbon 2012, 50, 5411-5420. [CrossRef]

92. Liu, J.; Liu, H.; Yang, T.; Wang, G.; Tade, M.O. Mesoporous Materials for Advanced Energy Storage and Conversion Technologies. Chin. Sci. Bull. 2014, 59, 2186-2190. [CrossRef]

93. Piedboeuf, M.-L.C.; Job, N.; Aqil, A.; Busby, Y.; Fierro, V.; Celzard, A.; Detrembleur, C.; Léonard, A.F. Understanding the Influence of Surface Oxygen Groups on the Electrochemical Behavior of Porous Carbons as Anodes for Lithium-Ion Batteries. ACS Appl. Mater. Interfaces 2020, 12, 36054-36065. [CrossRef] [PubMed]

Publisher's Note: MDPI stays neutral with regard to jurisdictional claims in published maps and institutional affiliations.

(C) 2020 by the authors. Licensee MDPI, Basel, Switzerland. This article is an open access article distributed under the terms and conditions of the Creative Commons Attribution (CC BY) license (http://creativecommons.org/licenses/by/4.0/). 